University of Louisville

ThinkIR: The University of Louisville's Institutional Repository

$5-2009$

\title{
The exploration of color theory in museum education using works found in the J. B. Speed Museum's collection.
}

Jonathan Ratliff 1986-

University of Louisville

Follow this and additional works at: https://ir.library.louisville.edu/etd

\section{Recommended Citation}

Ratliff, Jonathan 1986-, "The exploration of color theory in museum education using works found in the J. B. Speed Museum's collection." (2009). Electronic Theses and Dissertations. Paper 1183.

https://doi.org/10.18297/etd/1183

This Master's Thesis is brought to you for free and open access by ThinkIR: The University of Louisville's Institutional Repository. It has been accepted for inclusion in Electronic Theses and Dissertations by an authorized administrator of ThinkIR: The University of Louisville's Institutional Repository. This title appears here courtesy of the author, who has retained all other copyrights. For more information, please contact thinkir@louisville.edu. 
THE EXPLORATION OF COLOR THEORY IN MUSEUM EDUCATION USING WORKS FOUND IN THE J.B. SPEED MUSEUM'S COLLECTION

\author{
By \\ Jonathan Ratliff \\ B.A., Georgetown College, 2007

\begin{abstract}
A Thesis
Submitted to the Faculty of the

Graduate School of the University of Louisville In Partial Fulfillment of the Requirements

For the Degree of
\end{abstract}

Master of Arts

Department of Fine Art

University of Louisville

Louisville, Kentucky

May 2009 
Copyright 2009 by Jonathan Ratliff

All rights reserved 
THE EXPLORATION OF COLOR THEORY IN MUSEUM EDUCATION USING WORKS FOUND IN THE J.B. SPEED MUSEUM'S COLLECTION

\author{
By \\ Jonathan Ratliff \\ B.A., Georgetown College, 2007
}

A Thesis Approved on

April 2, 2009

by the following Thesis Committee

Thesis Director 


\section{DEDICATION}

This thesis is dedicated to all who read it. 


\section{ACKNOWLEDGMENTS}

First off, I would like to thank my mother. She is my rock and keeps me from going crazy. I would like to thank both of my parents for raising me with a strong emphasis on education, and being supportive when I decided to make a living in the art world. I would like to think Dr. Juilee Decker, Art History professor at Georgetown College, for making art so much fun. I would also like to think Joel Javier for showing me the ropes in museum education. I would like to think my thesis committee, especially John P. Begley, who suffered through this with me, and gave the most constant feedback needed to make this thesis what it is. Finally, I would like to think the countless others who have helped me along my educational journey and with this thesis. There are a lot of people to whom I owe a lot. 


\section{ABSTRACT \\ COLOR THEORY IN MUSEUM EDUCATION USING WORKS FOUND IN THE J.B. SPEED MUSEUM'S COLLECTION \\ Jonathan Ratliff}

April 7, 2009

Color is an important part of art and life, which can be utilized by the museum educator to engage visitors with the art. For the museum educator, development of appropriate programs and activities to meet the needs of their audience is a central component of their responsibilities. Therefore employment of important characteristics of art, such as color, to accomplish these goals is of vital importance.

To demonstrate how an educator can utilize color, I have developed a tour using the Speed Art Museum's collection. Although it is written specifically for one collection, the ideas can be translated to other institutions. Since school groups are among the most frequent and consistent visitors for many institutions, I designed this particular tour for the fourth and fifth grade level. To make this tour able to engage students as much as possible, and have a lasting affect, I have designed a variety of activities and discussion questions to accompany the artwork. All of these activities present color as a fascinating and approachable path for connecting the students to art.

Before presenting my tour, I approach color from a variety of different angles: historically, theoretically, culturally, scientifically, psychologically, physiologically and logistically. Each of these sections shows the importance of color, through a 
different sector of life. They show that color isn't just artistic, but important to every aspect of life.

Within the ideas section, I review the varying philosophies. I cite the thoughts of many important thinkers, including Johann Wolfgang Von Goethe, Gustave Moreau, Wassily Kandinsky, Helen Keller, Josef Albers, Johannes Itten, Carlos Cruz-Diez and David Batchelor. These scholars discuss the importance and influence of color, to both themselves personally and society at large.

After explaining the role of color thoroughly, I then am ready to do a walkthrough of my tour. I discuss primary colors, warm and cool colors, complementary colors, analogous colors, black and white and grayscale colors, neutral colors and the individual affects of red, white, yellow, gold, green, black and blue. Here I present info on each of the chosen artworks.

I give some tips on how to give the tour most successfully, including suggesting activities for docents to use on the tour. These activities are important to engage the children and to make a lasting impression for art and color.

Finally, I explain the practical application of the tour as I explain how I gave it to a $4^{\text {th }}$ grade class myself. I discuss how things went, what worked and what didn't. I prove that the tour is both applicable but successful in teaching a group more about color theory. 
TABLE OF CONTENTS

PAGE

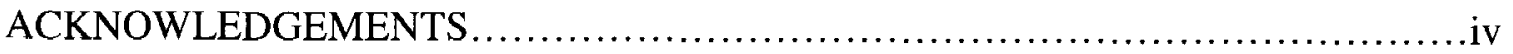

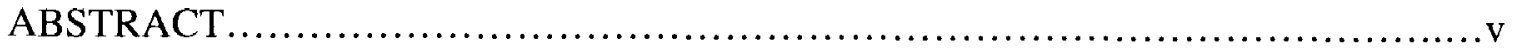

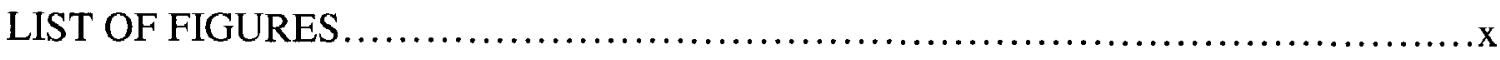

PART ONE: WAYS OF THINKING ABOUT COLOR

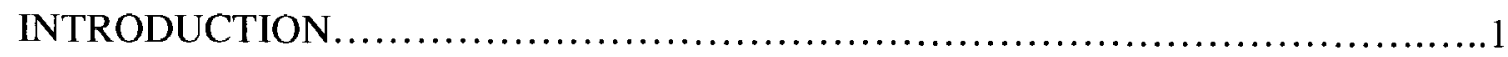

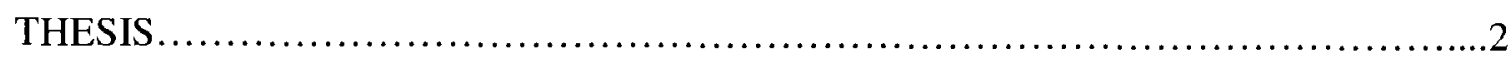

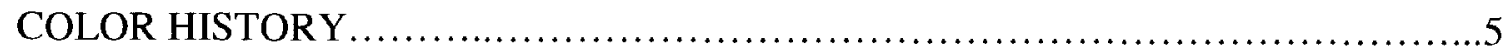

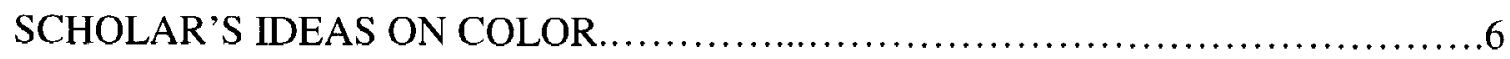

Johann Wolfgang Von Goethe.............................................

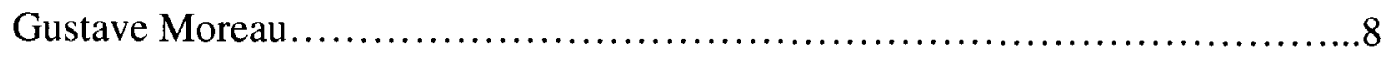

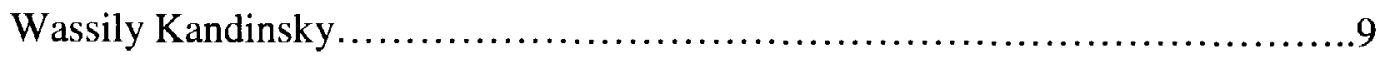

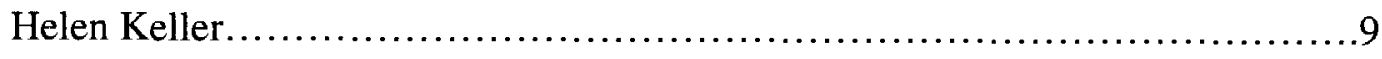

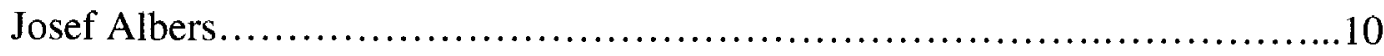

Johannes Itten........................................................ 11

Carlos Cruz-Diez....................................................11

David Batchelor........................................................11

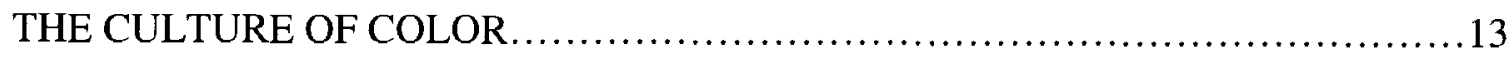

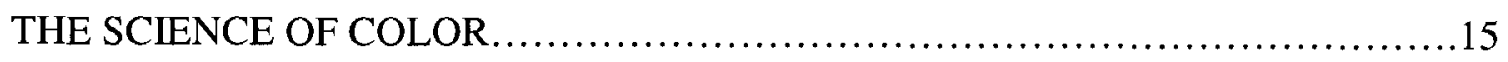

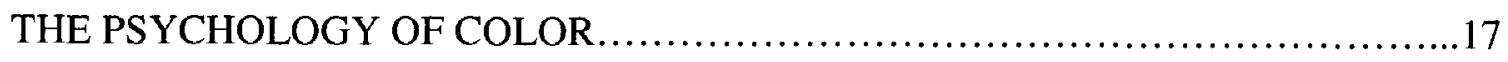

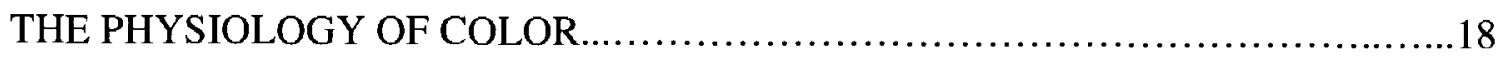




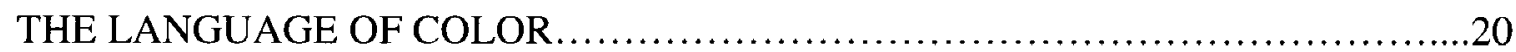

PART TWO: EXPLORING COLOR IN ART: THE TOUR

THE WALKTHROUGH.............................................................

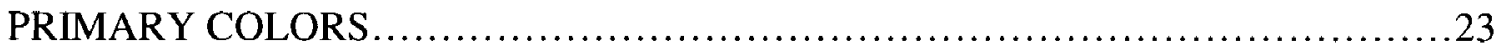

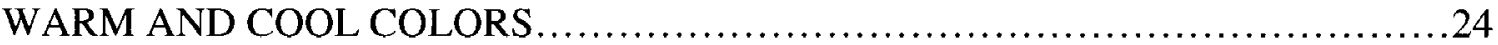

COMPLEMENTARY/SECONDARY COLORS .................................25

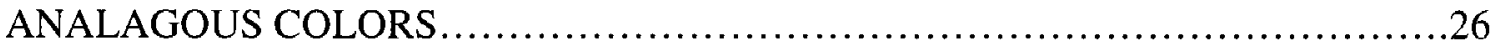

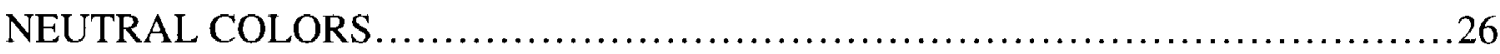

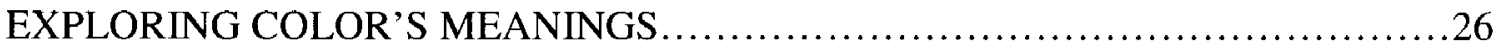

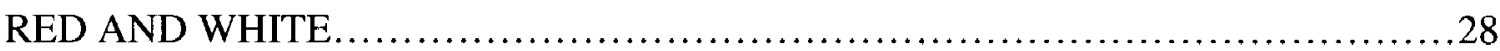

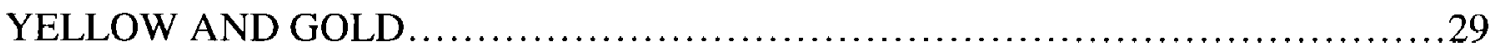

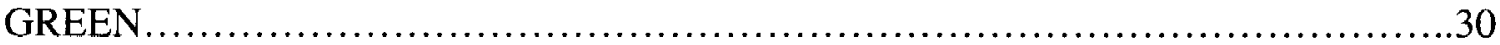

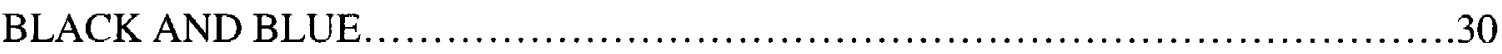

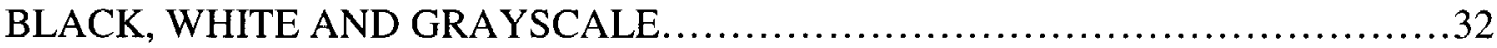

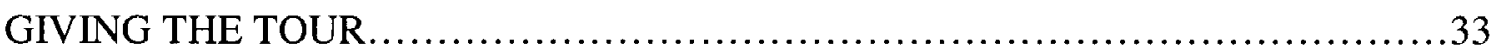

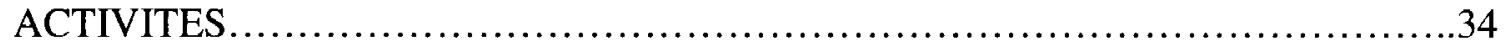

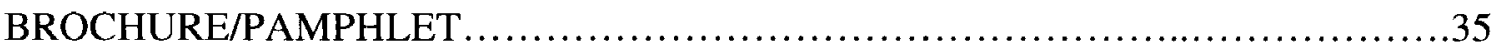

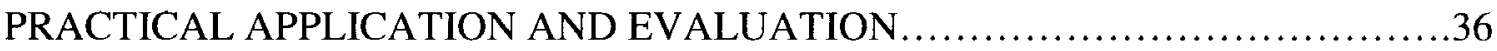

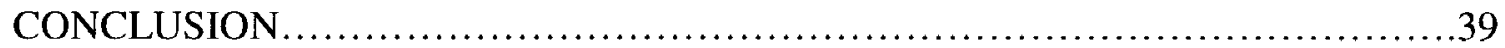

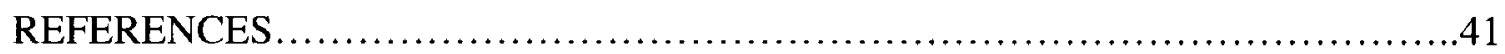

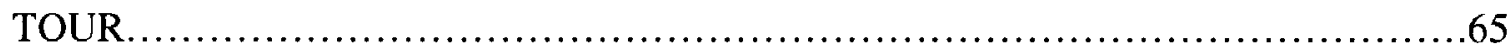

OBJECTIVES AND TEACHING TIPS............................................66 
WORKING WITH INTERMEDIATE STUDENTS: GRADES $4 \& 5 \ldots \ldots \ldots \ldots \ldots . \ldots 8$

PARTICULARS IN GIVING THIS TOUR......................................

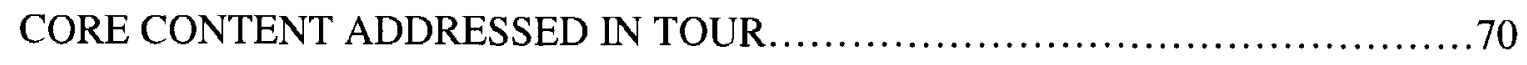

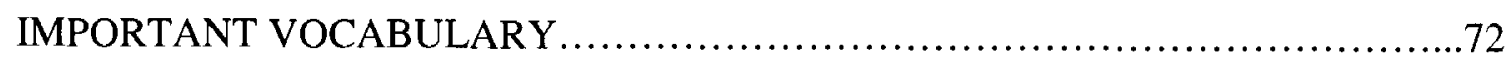

PART ONE: EXPLORING COLOR REALATIONSHIPS $\ldots \ldots \ldots \ldots \ldots \ldots \ldots \ldots \ldots \ldots \ldots$

PART TWO: EXPLORING COLOR'S MEANINGS ..............................85

APPENDIX

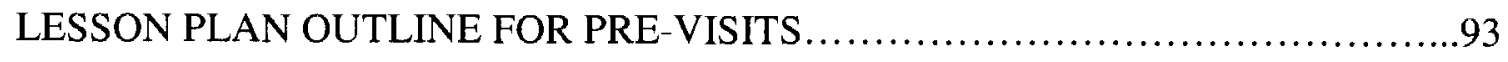

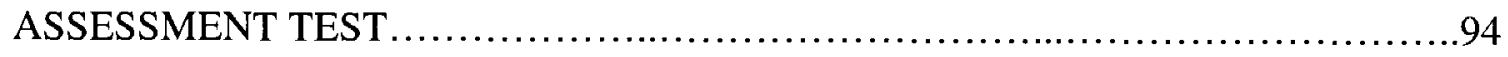

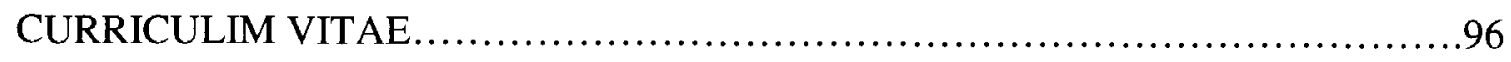




\section{LIST OF FIGURES}

FIGURE

PAGE

1. Quiver and Bow Case with Arrows, War shirt, and Quirt.

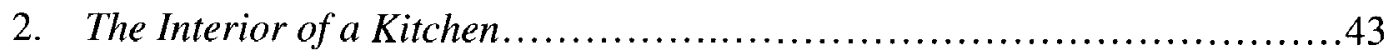

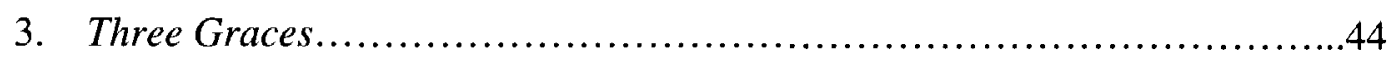

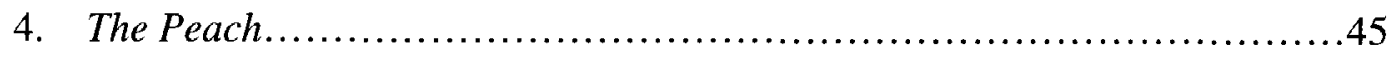

5. The Church at Varengeville, Grey Weather..............................46

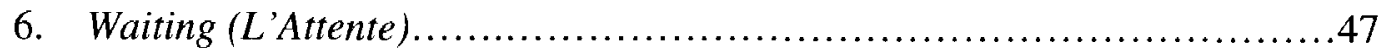

7. Raspberries............................................................48

8. Untitled (Talk Like Us),................................................49

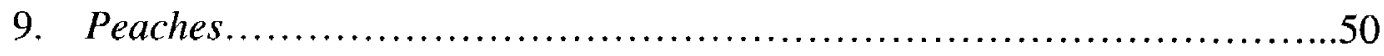

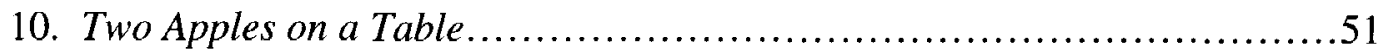

11. Portrait of a Forty-Year-Old Woman..................................52

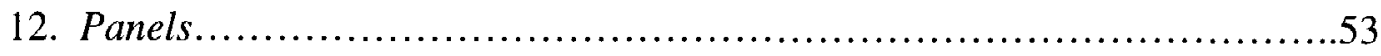

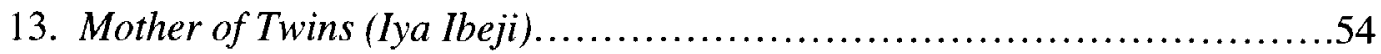

14. Portrait of Madame Houbigant, born Nicole Deschamps...................55

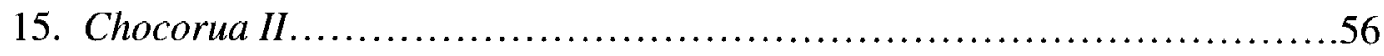

16. Interior of Santa Sophia, Constantinople ...............................57

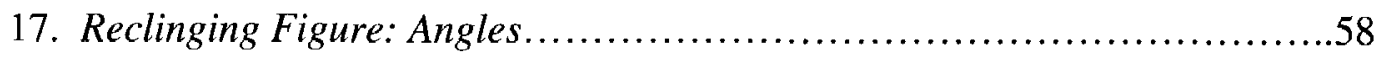

18. Landscape wit a Mill with a View of Montmarte............................59

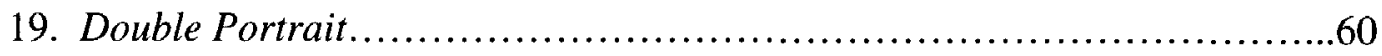


20. Waiting for the Ferry at the falcon Tavern...........................61

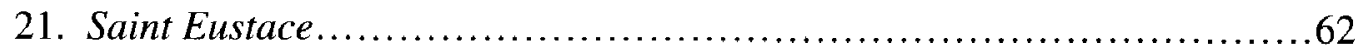

22. Woman in the Studio (Jacqueline Roque)...........................63

23. Color Wheel.................................................. 74 


\title{
PART ONE: WAYS OF THINKING ABOUT COLOR
}

\author{
Introduction
}

Recently, I was taking a tour at the Speed Art Museum. An experienced docent was giving a group of docents in training and me, some pointers on how to deal with children. One thing she said, in particular, stayed with me: "If you are talking to them and they are just not engaged, ask them if their favorite color is in the work." This hit me as a stroke of genius. Color is a great equalizer. Everyone knows color. Everyone has experienced color. Everyone feels comfortable with color. Color is simultaneously simple and complex; children learn to identify color and interact with it at a very early age and there are hundreds of scholarly works and experiments concerning the intricacies of color and numerous scientific experiments have been developed to understand how it works over the past century alone. Color is a valuable tool for curators and museum educators to use to engage visitors.

To most people color seems like a very simple thing, and they often do not realize how much it deeply affects their lives. They recognize its symbolic use (red is usually the color of anger), they understand its meanings (stop at a red light), they make associations (red slushy is cherry) and they are affected by it (the red walls of a room unsettle them). However, color is much more complex than most people realize, and it holds a large and important place in the world, particularly the art world. For this reason it is an important subject of study, one which the art museum is particularly well suited to 
provide. The art museum should play a role in the education of people about how color plays both in art and by extension in their daily lives. Using art on display and guiding visitors with a docent led tour is an easily accomplishable method to provide a pleasant and entertaining experience that allows museum visitors to learn its nuances and to discover for themselves its meanings.

Color is an omnipresent part of society. It affects people's health, mood, performance and emotions. As John Gage, a significant art historian, said, "Colour is implicated in physics, in chemistry, in physiology and psychology, as well as language and philosophy; yet it is visual art alone that has engaged simultaneously with most or all of these branches of knowledge and experience."1 Consequently, one of the things, with which color is most often associated, is visual art.

$\underline{\text { Thesis }}$ Art museums, and their education and other special programs, exist for the betterment of the community. Diane Quinn, manager of educational programs, from the Burke Museum of Natural History and Culture says, "A coherent, diverse list of offerings helps us make more of the museum's resources available to the public. Exhibits alone can't touch the wealth of information and expertise housed here." ${ }^{2}$ Therefore development of visitor tours can be an important component in expanding access to a museum's collections for its visitors. My tour, Exploring Color through the Art of the Speed Art Museum, will serve as one of many ways the Speed can enhance the experience of its visitors and broaden how they look at the art.

\footnotetext{
${ }^{1}$ Gage, Color in Art 7.

${ }^{2}$ Burton xvii.
} 
In the art museum understanding how color is used to shape, compose and arrange the ideas contained in the art is vital to comprehension and enjoyment of the art. The primary role color plays in composition through its multiple roles - formal, emotional as well as symbolic and narrative makes it crucial to understanding an artwork's content. The art museum educator should guide the museum visitor to an understanding of color. By leading visitors to evaluate color, they allow people to learn more about the art, themselves, and society at large. Comprehending color theory and using it to help analyze an artwork is an important step in leading visitors to a higher level of understanding.

Color can serve as a simple, efficient and engaging tool to help visitors of all ages learn more about not only art, but their own physical and mental makeup, their community's history and culture, and the human condition in general. By focusing on color, visitors will be encouraged to think about a major force in the world that perhaps they take for granted, but one that influences and shapes their lives daily.

The importance of color creates an excellent connection between society and art which can be used by the museum staff to engage museum visitors in their collections. As a subject appropriate for major professional studies, as well as parlor room conversation, color is one which everyone will enjoy and feel comfortable exploring. The art educator can tap into people's natural comfort with and attraction towards color, and use color's presence in art to bring people and art together. Using color focused activities, tours and talks they can bring about experiences that are crucial portals to understanding art itself.

I have constructed a tour that presents many aspects of various theories of color and explains how each of them can be helpful in engaging museum visitors. With activities designed to appeal to audiences ranging from pre-school children to educated 
and experienced professionals in the fields of art, science, design, economics, psychology, sociology and history, my tour connects people, directly, with color as well as demonstrates my point on the significance of color.

It makes perfect sense to use color as a way to engage children and museum visitors- whether children, new or novice adults and even sophisticated patrons. In reviewing the professional literature in my research for the development of this tour project, I found few tour examples or programs which utilize color as a primary approach to introducing visitors to museum collections. In the way my tour uses color as a primary tool for engaging visitors, I believe it can serve as a model method for enticing visitors to become involved with art and therefore is groundbreaking in its effort to pioneer a new way to connect viewers with art.

The "Exploring Color" tour presented in this thesis is specifically designed for a fourth or fifth grade class, but can easily be modified for any age group. Every Kentucky grade level is expected to grow in its knowledge of color as part of the goals and objectives of its core curriculum in the arts and humanities, so focusing on color for the tour makes it appropriate and attractive to teachers. Additionally, art curriculum is not the only thing being addressed in this tour. Learning how light interacts with surfaces is included in the learning goals of the science curriculum. Many historical and cultural ideas relevant to the core content learning outcomes are also addressed in the tour. Teachers will be able to use this tour for both subject specific core curriculum information and the critical and analytic thinking skills that are also parts of the Kentucky's educational goals. 
This tour is designed to utilize the artwork and collections of the Speed Art Museum. Using art usually on display, it addresses a variety of topics such as primary colors, warm and cool colors, complementary colors, grayscale, neutral colors, analogous colors and the associative effects of the most basic colors, red, blue, yellow, green, black and white as well as emotional, cultural and historical ideas about color. It focuses on twenty-two of the Speed's most important and diverse artworks and is accompanied by pre- and post visit discussion topics, questioning strategies and hands-on activities designed to help the visitor's understanding and enjoyment of the works and collection as a whole. Through a tour focused on learning about the workings of color in art, something as simple as naming your favorite color can become the beginning point for understanding art, self and society.

\section{Color History}

Color seems to have a universal human quality, for color has always been vital to art and society. In the beginning color was used to convey symbols, both religious and social. Cavemen used color at the very beginning of art. They used color to make their cave paintings more realistic, granting them more magical powers. They ground up and used pigments from berries, plants, beetles and other things found in nature. ${ }^{3}$ They eventually found animal fat could be used as a binding to make the pigment more usable and permanent. Thus, the first paint was created.

Color symbolism has always been important in almost every culture, like color itself. One of the very first examples of widespread color associations being used for decoration and symbolism in a culture is on a Ziggurat of Ur. ${ }^{4}$ The Ziggurat was built

\footnotetext{
${ }^{3}$ Fabri 15.

${ }^{4}$ Fabri 62.
} 
between 2300 and 2180 B.C.E., between modern day Baghdad and the Persian Gulf. The first story is black, the common color of the underworld, the second is red, symbolizing earth, on top of that is a blue shrine representing heaven and finally a gilded top, to represent the sun. ${ }^{5}$

The Great Temple of Nebuchadnezzar at Barsippa is another example of an ancient structure built and decorated with color symbolism in mind. It rises seven stages, each colored to represent a known planet at the time (the sun and moon included) : "The lower, which was also richly paneled, was black, the color of Saturn; the next, orange, the color of Jupiter; the third, red, emblematic of Mars; the fourth yellow, belonging to the sun; the fifth and sixth, green and blue respectively, as dedicated to Venus and Mercury, and the upper probably white, that being the color belonging to the Moon."

For a long while people paid little to no attention to concerns such as "What looks good together?" and "What colors do I like?" During the Renaissance they began to shift their way of thinking ${ }^{6}$, and began to include these concerns when creating art. ${ }^{7}$ By the 1800 's artists and psychologists alike began to experiment on the effects color had on people.

\section{Scholars Ideas on Color}

The phenomenon of color is a complex and confusing one, and when first studied was much more anecdotal than scientific. But a varied cast of noted artists and intellectuals have explored and theorized on color. They approach it from a variety of points of view; pure theory to application, experiential to religious.

\footnotetext{
${ }^{5}$ Birren 7.

${ }^{6}$ Birren 1.

${ }^{7}$ Fabri 18.
} 


\section{Johann Wolfgang Von Goethe}

Johann Wolfgang Von Goethe, an important color theorist once said,

"Few of us can remain insensitive to the alluring quality of colors spread all over the entire visible realm of nature. These create delight and manifest pleasant impressions to the eye even without reference to their structure. The simple green of a freshly mown meadow is a satisfactory sight, even though it is nothing but an unimportant surface. And a somewhat distant forest of a broad and uniform mass has a salutary effect on the eye." 8

He also commented on the associations and meanings we have with color, in relation to dress. "In dress we associate the character of the color with the character of the person. We may thus observe the relation of colors singly, and in combination, to the color of the complexion, age and station." Society has endless associations between colors and who wears them. We immediately make a judgment on someone's personality whether he, or she, are wearing all black or bright and vibrant colors. It would be odd for a little boy to be dressed in pink or for a woman to wear a red dress to a funeral. These associations are present in our psyche, engrained by society.

In Goethe ${ }^{9}$ a theory is introduced that describes this as a progression of three phenomenological experiences. The first is the pure phenomenon, "which each man becomes aware of in nature." Next comes the scientific phenomenon, "through experimentation, as a result of which it becomes known in other circumstances and conditions, and is presented in a more or less fortunate sequence." Finally, we go back to the pure phenomenon which "exists as a result of all experiences and experiments. It can never be isolated; rather it shows itself in a steady sequence of appearances. In order to

\footnotetext{
${ }^{8}$ Matthaei 14.

${ }^{9}$ Matthaei 65.
} 
show it, man's mind determines the empirical vacillation, excludes the coincidentalrather, the impure-unravels the entangled, even discovers the unknown."

Goethe identified three different kinds of colors: physiological colors, physical colors and chemical colors. Physiological colors are "colors of the eye." These form the foundation of color theory, and are ancient in origin. "They have been hitherto looked upon as extrinsic and casual, as illusion and infirmity." Physical colors are those "which are produced by certain material mediums." These mediums don't have color of themselves, but instead reflect and divide light. Examples include prisms, waterfalls and bubbles. Finally, (and most recently) there are some chemical colors. These are colors we humans can produce and control. Each is different and distinct in how they come about and how we perceive them.

An interesting theory on complementary colors is proposed in Goethe's Color Theory. ${ }^{10}$ Each pair of complementary colors serves as the pole ends to an element of color. Orange is the warmest color, while blue is the coolest. This makes the orange-blue pole that of color temperature. The yellow-violet continuum is one of value, with purple being the darkest and yellow being the lightest. Finally red and green have the most and least intensity, respectively.

\section{Gustave Moreau}

"Note one thing well: you must think through colour, have imagination in it. If you don't have imagination, your colour will never be beautiful. Colour must be thought, dreamed, imagined ..." Gustave Moreau once said in his 1893 work, On Colour. It touches on the complex relationship humans have with color, how the perception of it is

\footnotetext{
${ }^{10}$ Matthaei 56.
} 
so different than anything else we can see. It is one of the few perceptions which cannot be confirmed with another sense.

\section{Wassily Kandinsky}

In his Concerning the Spiritual in Art" Wassily Kandinsky "states the psychological effect of color as one of the main consequences to the contemplation of color. The psychological power of color becomes apparent, calling forth a vibration from the soul. Its primary, elementary physical power becomes simply the path by which color reaches the soul." He really focuses on the power color has over us, and makes it a spiritual and Godly force. He goes on to talk about associations and how red has a similar effect as flame on the human psyche and how we can associate yellow with the sourness of lemons.

Kandinsky also speaks of the extreme power of blue, once again likening the experience of color to a spiritual one: "The inclination of blue to depth is so strong that its inner appeal is stronger when its shade is deeper. The darker the shade of the blue color, the stronger is its call into the Infinite, the stronger is the yearning for Purity and finally for the Transcendental."12

\section{Helen Keller}

Color is such a major force in human perception that even people who can't perceive it have to take its effects into consideration. Helen Keller, who was both blind and deaf once said "It strains my mind to separate color and sound from objects." related perception of colors to smell and taste. "I understand how scarlet can differ from

\footnotetext{
${ }^{11}$ Kandinsky 88.

${ }^{12}$ Pigments Through the Ages.

${ }^{13}$ Sargent 18.
} 
crimson because, I know that the smell of an orange is not the smell of a grapefruit." Colors are indeed infinitely varied, as is smell.

\section{Josef Albers}

One of the best known color theorists of the $20^{\text {th }}$ century was Josef Albers ${ }^{14}$. In his book "Interaction of Color" Albers makes a very interesting statement in the introduction: "In visual perception a color is almost never seen as it really is - as it physically is. This makes color the most relative Medium in Art." For example if someone says "red" to fifty people, it will conjure up a different hue in each persons mind. One person may think of a deep crimson while another thinks of a bright scarlet. Similarly if a woman has on a light bluish-purple blouse, she might call it lilac, while a friend may call it violet and her husband calls it periwinkle. Albers states that the human eye can not clearly tell the difference between different tones of a hue. There are relatively few (usually around twelve) colors which can be conveyed through speech.

Perhaps the thing Albers is best known for is studying how colors look different as they are placed upon a field of other colors. He explored this in his art with many series of concentric squares of various solid colors. If two gray squares of the exact same hue, value and intensity are placed respectively on larger squares of blue and orange, the human eye will interpret them differently. The gray square placed on a blue background will seem warm, while the one on orange will seem cool. The surrounding colors intensify what is different about the central color. "Color deceives continually," Albers states.

\footnotetext{
${ }^{14}$ Albers 1.
} 


\section{Johannes Itten}

Johannes Itten, a contemporary of Albers and one of the most influential color theorists of the $20^{\text {th }}$ century, wrote

"Color is life; for a world without colors appears to us as dead. Colors are primordial ideas, children of the aboriginal colorless light and its counterpart, colorless darkness. As flame begets light, so light engenders colors. Colors are the children of light, and light is their mother. Light, that first phenomenon of the world, reveals to us the spirit and living soul of the world through colors." 15

Itten elevates color's role to one of mediator of the human experience and the natural unknown. He places colors importance above all else in its ability to affect human wonder. He states, "Nothing affects the human eye more dramatically than the apparition of a gigantic color corona in the heavens. Thunder and lightning frighten us; but the colors of the rainbow and the northern lights soothe and elevate the soul."

\section{Carlos Cruz-Diez}

Color is not rational. Neither are humans rational in their response to color. As Carlos Cruz-Diez mentions in Reflections on Color ${ }^{16}$ why or people like, or don't like, a certain color has no basis in logic. Someone simply doesn't like a certain shade of red, paired with a certain shade of yellow, because it aesthetically offends them. There is no grand explanation, they just don't like it.

\section{David Batchelor}

Chromophobia ${ }^{17}$ by David Batchelor explores the human prejudice against color. He presents color as an endangered force which is marginalized and hated. He says "purging of colour is usually accomplished in one of two ways. In the first, colour is

\footnotetext{
${ }^{15}$ Itten 13.

${ }^{16}$ Batchelor, Colour 111.

${ }^{17}$ Batchleor, Chromophobia 21.
} 
made out to be the property of some 'foreign' body - usually the feminine, the oriental, the primitive, the infantile, the vulgar, the queer or the pathological. In the second, colour is relegated to the realm of the superficial, the supplementary, the inessential or the cosmetic." He further explains "In one, colour is regarded as alien and therefore dangerous; in the other, it is perceived merely as a secondary quality of experience, and thus unworthy of serious consideration. Colour is dangerous, or it is trivial, or it is both. (It is typical of prejudices to conflate the sinister and the superficial.)"

Chromophobia, like color itself, has been part of culture since it began. There is evidence of the oppression of color dating back to Aristotle. Batchelor says "For Aristotle, the repository of thought in art was line. The rest [color] was ornament or worse." Drawing was order, and color chaos. Aristotle went so far as to refer to color as a pharmakon, a drug. He found color dangerous.

Batchelor goes on to discuss Charles Blanc, critic and color theorist from the 1890s. Blanc associated design and color with Adam and Eve, respectively. True to the nineteenth century attitude towards women, he said that design must hold a firm grasp over color, or color will bring about the downfall of art, as Eve brought about the downfall of mankind. If this isn't blatant color prejudice, I don't know what is. Blanc believed there to be only two possible paths to avoid this fall. The first is abandoning color all together, the second, controlling color. "Conform, subordinate, control." Like all prejudices these are the courses of action for those who hate and fear color.

In "Chromophilia" ${ }^{18}$, Batchelor explores the other side of the problem. Color has at many times been loved and used very advantageously. According to Batchelor it is in the sixties when color experiences a rebirth, and become a central element in art. Abstract

\footnotetext{
${ }^{18}$ Batchleor, Chromophobia 97.
} 
Expressionists, Pop Artists and Color Field Painters all used color to its full effect. They used color, as color, not to represent something in nature more realistically. House paint and screen printers ink were used in solid unmixed areas and, of course, many of these artists were criticized for their use of color. This is the nature of Chromopobia.

In "Apocalypstick"19, also in Chromophobia, Batchelor compares color to such things as gems and flowers, unneeded but beautiful. An interesting comparison, which is at the center of his writing, is color's relationship to make-up. Art and the world are like a woman's plain flesh-toned face, beautiful in its own right, but both simultaneously enhanced and ruined by the unnecessary use of color.

In Chromophobia ${ }^{20}$, Batchelor writes an entire section on the color white, "Whitescapes." In it he explains the complexities of the color white. He presents white's pureness as sinister, bringing out its inaccessibility and overpowering plainness. Indeed, white does seem to use its purity to keep distance. A white gallery space seems much more hoity than a colored one. It is less engaging and more shrine-like.

\section{The Culture of Color}

Although, it cannot be proved, mystics in the past and today hold that each individual gives off a colored aura. ${ }^{21}$ These auras are said to be a variety of different colors, and each represents how the person is feeling. In there theories, white is the perfect color, it signifies balance. Bright colors are also very good, but not as balanced. Each tells something about the individual: red is vigor, yellow is health, violet is for those looking for a religious experience, etc. Dark, dingy, grayed and muddy colors are the least desirable and can signify depression and disease.

\footnotetext{
${ }^{19}$ Batchelor, Chromophobia 51.

${ }^{20}$ Batchelor, Chromophobia 9.

${ }^{21}$ Birren, 69.
} 
There is also strong reference to the use of colors religiously, in the JudeoChristian and Muslim traditions, and philosophically, in both western and eastern thought. Ethel Rompilla discusses this in her book Color for Interior Design ${ }^{22}$ (in itself an example of the variety of ways color theory comes into play.) In early Christianity, she says "red stood for compassion and martyrdom, blue for divinity, white for purity and joy, green for immortality, yellow or gold for celestial glory, and purple for sorrow. The trinity of father, son, and holy ghost was represented by blue, yellow and red."

The Chinese associate the cardinal directions with colors: north (black), east (blue/green), south (red), west (white) and center (yellow). The ancient Greeks believed the world to be made up from four elements, each associated closely with a color: earth (green), air (yellow), fire (red) and water (blue). The ancient Greek philosopher Empedocles felt that the universe was composed of a mixture of the four elements similarly that all colors were mixed by the primaries. Muslims associate certain colors with both the four elements and the seasons: spring and fire (red), summer and air (yellow), autumn and water (green) and winter and earth (blue). Although the colors seem somewhat arbitrary, and vary between cultures, it is extremely important that they were used in art and philosophy to communicate ideas, in every culture. ${ }^{23}$

Although it is true that color has always been vital to art and culture, it has become even more so in the past one hundred years. In the exhibition catalog for the show "Seeing Red" 24 the editors make a strong, however true statement: "The history of abstract and nonobjective art in the $20^{\text {th }}$ century is in many ways related to the evolution of theoretical ideas on color." Indeed many important $20^{\text {th }}$ century art movements focus

\footnotetext{
${ }^{22}$ Rompilla 67.

${ }^{23}$ Golden, 40, 63.

${ }^{24}$ Fehr and Wurmfeld 9.
} 
heavily on color: abstract expressionism, color field, pop art, Plasticism, Supremacism and others. Even the first stage of abstraction, Impressionism, dealt with colors in a way that had never been seen before: "Color has always been important to art, but it has been a primary means since the second half of the nineteenth century when it was opened and explored by the Impressionists and Post-Impressionists" says William C. Agee in his essay "More on Red: Color in America, 1910-1945/Prelude and Reflection," also in the "Seeing Red" catalog. ${ }^{25}$

One of the simplest ways to see the importance of color in culture today is to go to a wedding. In the western world, the Bride wears white, to symbolize purity, and something blue for good luck. If it is her second marriage, it is inappropriate for her to wear white. In India brides wear yellow garments on their wedding day, and also six days before to drive off evil spirits. In China red is the color for brides. The bride wears red, carries a red parasol, is carried in a red chair and has her family's name inscribed on lanterns, in red. Red and yellow are also traditional marriage colors in Egypt, Russia and the Balkans. ${ }^{26}$ Once again, although different cultures use different colors, they all recognize that color symbolism is important, and use it in their ceremonies.

\section{The Science of Color}

An important part of understanding color theory and its relation to art is to know the scientific background of color. In her book Vision and Art, Margaret Livingstone discusses the biology of seeing. ${ }^{27}$ She says,

"Light passes through the front of the eye, the pupil, and the lens focus the image to the retina, a sheet of layers of neural tissue that lines the back of the eyeball. The first layers are the ganglion, bipolar, and horizontal cells;

\footnotetext{
${ }^{25}$ Fehr and Wurmfeld 78.

${ }^{26}$ Birren 11.

${ }^{27}$ Livingstone 24.
} 
the cells that respond directly to light, the photoreceptors, are surprisingly, in the outermost layer. The photoreceptors contain light absorbing chemicals, pigments that generate a neural signal when they absorb light. The signals pass towards the front of the eyeball through the bipolar and horizontal cells to the ganglion cells, which send their signals from the eye via the optic nerve to the brain."

There are two kinds of objects we perceive: luminous and reflective. ${ }^{28}$ Things like sunlight and fire are colored themselves, while a chair, book or cat can only be seen if light is reflected off it. What color our eye perceives is dependent on what wavelengths an object either emits or reflects and which it absorbs. If a chair is green, it is absorbing all wavelengths but green. The green wavelengths are what are received by our eye.

The human eye has cones which serve as receptors and transmitters of color. There are three types of cones each specializing in interpreting a different wavelength of light: red (long wavelength, about $560 \mathrm{~nm}$ ), green (middle, $530 \mathrm{~nm}$ ) and blue (short, $430 \mathrm{~nm})$. With these three kinds of receptors the human eye can interpret over 10,000 different colors. Although there is rarely a defect with blue cones, red and green cones can be defective. This results in color blindness and effects how people perceive color.

In 1794, John Dalton, a British scientist and professor, became the first person to study colorblindness, shortly after discovering he didn't see colors as others did. He describes associating pink, purple and crimson with blue, seeing very little relation to red in any of them. He even describes not being able to tell a blue flower from a pink flower, and when he asked people, which it was, they always thought him joking. People are so sure that others perceive color as they do that such a question is laughable.

Science and art, although both concerned with color and light, have different ways of looking at things. Red, yellow and blue are the primaries of art, because artists can mix

\footnotetext{
${ }^{28}$ Sargent 27
} 
any color using these three pigments. Red, blue and green are the scientific primaries, due to those being the three types of cones in the human eye. Yet a third set of primaries are yellow, magenta and cyan (a turquoise-like color), which are used in graphic art and printing. All of these triads function the same way though and one can create all other colors from them, in their respective mediums of paint, light and ink.

When it was first realized that light and pigments did not share the same primaries many people, especially artists, were confused and upset. ${ }^{29}$ Arthur L. Guptill describes the difference. "When one spectral hue is added to another, light is added to light (brilliancy to brilliancy), so that when the spectral hues are merged, the result is bright, pure light. When a pigment of one color is added to a pigment of another color, however, each pigment having absorbed and annihilated some of the light illuminating it, dullness is, in a sense added to dullness."

\section{The Psychology of Color}

The psychological aspect of color is another aspect which must be considered. For many years psychologists have studied how colors affect their subjects. Carl Jung once wrote "vivid colours seem to attract the unconscious." 30 People react to color inadvertently as well as making conscious associations. A solid bright white room will affect your behavior whether you are aware of it or not.

I spoke with Dr. Paul DeMarco ${ }^{31}$, a psychology professor at the University of Louisville, who has interest and experience in the field of visual perception. His areas of expertise include researching which colors people are most sensitive to and studying

\footnotetext{
${ }^{29}$ Guptill 14.

${ }^{30}$ Batchelor, Colour, 91 .

${ }^{31}$ DeMarco.
} 
perceptual and behavioral responses to color. These areas are the easiest to study scientifically, while he states some other areas of color theory are more anecdotal.

DeMarco spoke about pure color, or colors that are their own with no other color presence, for example a yellow that has absolutely no trace of reds or greens. This concept is very similar to primary colors, which are pure and cannot be made using other colors. These "pure colors" are also more recognizable and distinguishable by the human eye.

A study Dr. DeMarco does commonly is subjecting subjects to a white light, and gradually adding color until the subject recognizes the color in the light. Some wavelengths of light are recognized quicker than others. If one was to graph wavelength of light, on the $\mathrm{x}$-axis, and the perceived intensity of the color, on the y-axis, there are definite peaks. These wavelengths (specific colors) are more recognizable. This shows that the human eye is more sensitive to some colors than others.

\section{The Physiology of Color}

While many colors have social and psychological meanings, associations and effects, some actually have very strong physical results. In Color and Human Response Faber Birren states "The reaction to color is not unlike the reaction to alcohol, tobacco, coffee - up for a short period and than down. ${ }^{, 32}$ Red and blue have the strongest reactions. Red can evoke a fight-or-flight response; raise blood pressure and make the heart beat faster. ${ }^{33}$ Blue can slow pulse rate, lower body temperature, and reduce appetite. The psychological associations mimic these physical reactions. Red is a color of

\footnotetext{
${ }^{32}$ Birren, 24.

${ }^{33}$ Graphic Design.
} 
excitement, blue one of calmness. The fact that these two colors in particular have such strong physical effects, may account for their popularity.

Birren gives an interesting account: "In 1875 a European doctor by the name of Ponza fitted several rooms with colored-glass windows, colored walls, and colored furnishings. Red and blue were the colors principally used. Regarding red he wrote, 'After passing three hours in a red room a man afflicted with taciturn delirium became gay and cheerful; on getting up the day after his entry into the room, another madman who had refused all food whatever asked for breakfast, and ate with surprising avidity.' As to blue, "A violent case who had to be kept in a straight jacket was shut in a room with the blue window; less than an hour afterwards he had become calmer."34

Color is so powerful, there are noticeable reactions to it from insects, fish, birds, plants and animals. ${ }^{35}$ Insects have a slightly shifted color perception, as compared to humans. They can't see red or orange, but they can see ultraviolet and other frequencies approaching x-rays which humans cannot. They are attracted to certain colors, mainly yellow-green and blue-violet. All fish have color vision, and all have a very strong reaction to red, either positive or negative. When placing two fish under pink (light red) and blue lights, the blue lighted fish produced no offspring. Perhaps most impressive is a study on the aggressiveness of mink. Minks were kept behind glass of blue and pink. Much like humans they reacted to blue with a calm demeanor and were far less violent. When kept behind pink glass (or light red) they became more aggressive and violent.

\footnotetext{
${ }^{34}$ Birren, 44.

${ }^{35}$ Birren 18.
} 
In "Color," Paul Zelanski and Mary Pat Fisher ${ }^{36}$ discuss the physical aspects of color. They touch on chromo-therapy, a practice of using color for medical results. They describe it as such: "People are bathed with colored lights, placed in colored environments, or asked to meditate on specific colors thought to stimulate particular glands." This practice dates back to the ancient Egyptians, Chinese and Indians.

There have also been extensive studies on color in decoration. Some places, namely hospitals, schools, apartments, dormitories and spaceships, are particularly drab and cause people within them to feel more dull, bored and frustrated. In his book, Color and Human Response, Faber Birren talks about these, hospitals and spacecraft in particular. ${ }^{37}$ There have been many studies which confine people in dark and enclosed spaces for a period, sometimes up to twenty-four days. There are mixed results, but in a study which placed seventeen volunteers in respirators for 36 hours, only five made it the entire duration. The others had such extreme reactions as hallucinations, panic attacks and hysterical fits. People need light and color to survive.

\section{The Language of Color}

In Vision and $\mathrm{Art}^{38}$ individual color perception is addressed directly in the insert "Do you see red like I see red?" While we all can agree that a fire truck is red, is the red we each see the same thing? Perhaps someone else perceives red as slightly oranger than you might, but there is no way of knowing, because aside from just a few solid color terms and thousands of subjective and unsure ones, there is no way to verbalize the experience of color. Color blindness is an example of this to the extreme which can be documented.

\footnotetext{
${ }^{36}$ Fisher and Zelanski 36.

${ }^{37}$ Birren 104.

${ }^{38}$ Livingstone 25.
} 
As discussed in "Color-Term Salience and Neurophysiology of Color Vision" by Andre Von Wattenwyl and Heinrich Zollinger ${ }^{39}$, colors are named in a certain order, in every language. Six colors-black, white, red, blue, yellow and green-always come first and other colors are added later as the language matures. Also, these six main colors are considered "primary color terms' by the authors, and for the most part, society at large.

In this article, we also see results of studies in color recognition and we see that cool colors are much more individualistic than warm colors. For example, red, orange and yellow run together without much difference between them. Orange is very obviously red and yellow mixed. Cool colors, however, have much more variation. Green, blue and purple are extremely distinct, and both hues found in between them (i.e. aqua or indigo) and tones of them (i.e. navy or lavender) are much more easily recognized and named.

An article from the same publication (American Anthropologist) written some twenty years later supports and expands on these ideas: "Color Appearance and the

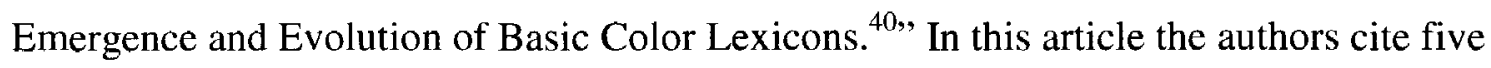
stages of development in color language. These are surprisingly the same in every language and they convey a lot about the hierarchy of color perception and importance.

Black and white come first, with the speakers just distinguishing between light and dark. The color terms are much more general in this stage though with white including warm colors and black including cool colors. Soon the word red is added, but includes oranges and yellows. Yellow and green (green also describes blue) are added next, and finally blue splits from green to become its own color.

\footnotetext{
${ }^{39}$ Wattenwyl and Zollinger 281.

${ }^{40}$ Kay and Maffi 743.
} 
Many times people debate whether a color is baby blue or sky blue, fuchsia or magenta or lavender or lilac, so that they miss the experience of the color. According to the US Bureau of Standards there are 125 English and French terms for mid-blue alone. As David Batchelor says in the introduction to his book Colour, "occasionally, there is an essay that attempts ... to indicate something of the infinitely rich variety of experience and association that is hidden under a simple colour term, such as "blue." Despite their being millions of tones, shades and mixtures of colors, in actuality, there are only about twelve that human language has named as basic colors. The simplest languages, as stated above, usually just identify black, white and sometimes red. The most advanced languages (in terms of color identification) have twelve; these languages include Italian and Russian. English identifies eleven of these. These colors are recognized as distinct, different and pure colors in each language which provides a name for them.

The twelve colors are red, orange, yellow, green, blue, violet, black, white, gray, brown, pink and light blue. In English, if we see light red we call it "pink." If we see light blue, however, and there is not a darker blue for comparison, we call it blue. In Italian however the colors blu (blue) and azzuro (light blue) are as distinct as red and pink in English. In Vietnamese and Korean, however, there is only one word for both blue and green, which are no different than scarlet and vermillion are to us. In a simple language white may refer to what we call, red, orange, yellow, pink and white. Color terminology is varied throughout cultures, so are cultural associations, but colors are always an important part of culture.

\footnotetext{
${ }^{41}$ Batchelor, Colour 18.
} 


\section{PART TWO: EXPLORING COLOR IN ART: THE TOUR}

\section{The Walkthrough}

The works I have chosen to be in the tour each have an important role and contribution. Primarily, each is a good representative of a color or color realationship. Secondly, they come from a variety of different time periods, geographical locations and styles. This helps highlight the collection as a whole while focusing on a specific aspect of it related to different ideas about color. Both of these, the representation of a color scheme and diversity in time periods, locations and style, help support the core content and state standards which target school-aged children, some of the museums primary visitors.

The tour is split into two distinct parts. There two parts can be used separately as two shorter tours. The first deals with color relationships and focuses more on basic theories and core content. The second focuses on individual colors and utilizes critical thinking.

\section{$\underline{\text { Primary Colors }}$}

The first concept in the tour is primary colors. Primary colors are the basic building blocks of color; therefore the perfect place to begin. The primary colors of pigments are red, yellow and blue and they are the only distinct colors, besides white (which is the reflection of all colors) and black (no color). All other colors can be mixed from a combination of these five basic colors. 
The works I chose to feature in this tour section are the Sioux Quiver and Bow Case with Arrows, War shirt, and Quirt ${ }^{42}$ and Interior of a Kitchen ${ }^{43}$ by Van Slingelaid. These two exemplify primary colors in very different ways. Van Slingelaid's work is a Dutch painting and has the three colors incorporated into the clothing of the central figure. The colors are bright and crisp and easily display a working color triad as each of the colors make the other two more vibrant. The war shirt on the other hand simply has the primary colors in the bead work. Here the primary colors function less as a triad and more as building blocks. Out of all the colors the Native Americans could have used they chose the basic ones, instinctually knowing they were the most different distinct colors.

\section{$\underline{\text { Warm and Cool Colors }}$}

The next concept to be covered is warm and cool colors. These terms are particularly important in art criticism, because when we view an artwork the color temperature affects how we perceive it and what we think of it. Warm colors pop out and bring a sense of excitement; cool colors recede and have a calming affect on the viewer. Yinka Shonibare's Three Graces ${ }^{44}$ and Joseph Stella's The Peach ${ }^{45}$ both have warm colors that draw the eye in and convey emotion. The graces seem to be moving in their red garments. Even though other colors are present the rich reds and golds capture the viewer's eye causing a sense of excitement and even urgency. In The Peach the warm colors are broken with the placement of the blue plate. This changes the dynamic of the painting entirely.

\footnotetext{
${ }^{42}$ Figure 1

${ }^{43}$ Figure 2

${ }^{44}$ Figure 3

${ }^{45}$ Figure 4
} 
Cool colors, as exemplified by both The Church at Varengeville, Grey Water ${ }^{46}$ and Waiting (L'Attente) ${ }^{47}$ by Claude Monet and Marc Chagall, respectively, recede and cause the viewer to relax and become calm. The blues, greens and purples convey somber emotions like sadness. Waiting in particular strongly conveys a sense of melancholy and longing. The prominent blue and deep green portray the feeling and meaning of the work as much as the forms do.

\section{Complementary/Secondary Colors}

Complementary colors are another basic color scheme. Colors opposite on the color wheel (i.e. red and green, blue and orange, yellow and purple) enhance each other, making the opposite color its optimum intensity. Some good examples of this are William Mason Brown's Raspberries ${ }^{48}$ and Untitled ${ }^{49}$ by Barbara Kruger. These are two interesting examples of complementary colors. Raspberries's colors are more truly red and green, while Kruger's work displays a more pink and aqua coloring. This shows the more complex side of complementary colors, and proves that colors don't need to be exact opposites to enhance one another.

While discussing complementary colors, secondary colors should be mentioned. Every primary's complement is the secondary formed from the mixture of the other two primaries. For example, red's complement is the mixture of blue and yellow: green. Also, the secondary colors form a color triad, like the primary colors.

\footnotetext{
${ }^{46}$ Figure 5

${ }^{47}$ Figure 6

${ }^{48}$ Figure 7

${ }^{49}$ Figure 8
} 


\section{Analogous Colors}

Analogous colors can be difficult for some to understand. Analogous colors are colors adjacent on the color wheel, like red, orange and yellow or yellow, green and blue. The idea of a color scheme of colors linked together on the color wheel is harder to grasp than concepts like primary colors and warm and cool colors. It is a concept which may need to be explained more. The paintings chosen to model the analogous color scheme are ones which do so clearly and simply, to help the tourists understand the concept. Peaches $^{50}$ by William Mason Brown and Paul Cezanne's Two Apples on a Table ${ }^{5 l}$ both display a simple analogous scheme. They both have oranges, yellows and greens, with very little to no reds, violets or blues.

\section{$\underline{\text { Neutral Colors }}$}

Portrait of a Forty-Year-Old Woman ${ }^{52}$ by Rembrandt is not only one of the Speed's most prized artworks but it is also a good example of neutral colors. It consists of black, white and flesh tones. Also, African pieces like the Yoruba Doors ${ }^{53}$ or Mother of Twins (Iya Ibeji) ${ }^{54}$ are comprised almost entirely of brown. Here the focus should be on why the artist utilized neutral tones or how is the lack of color is different between Baroque Dutch and African art.

\section{Exploring Color's Meanings}

While the first half of the tour focuses on color schemes and showing functional examples of them, the second half focuses in on specific colors and their effects. The colors can affect the mood of the viewer or convey meaning by itself, just as they can in

\footnotetext{
${ }^{50}$ Figure 9

${ }^{51}$ Figure 10

${ }^{52}$ Figure 11

${ }^{53}$ Figure 12

${ }^{54}$ Figure 13
} 
relationship groups. Although all colors have connotations and affects, for the sake of brevity this tour only focuses on the six colors, which are most individual and distinct and are recognized as the most common colors: red, blue, green, yellow/gold, black and white.

While generally each color affects everyone in similar ways, such as blue calming us or red exciting us, we each also can be individually affected by color. The elusive shade we call our favorite color is very important to us. We get great delight from our individual favorite color. We each have a feeling of delight when we encounter this color. Some people love green, and therefore love the springtime even more than others.

Although, many people have many different favorite colors, when asking a large group of people to choose among the six principle hues, the colors will almost invariably rank in the same order: blue, red, green, violet, orange, yellow. There are just a few cases where this will change. Women prefer yellow over orange. American Indians prefer red and violet over blue and green, respectively. Filipinos generally don't like blue as much as other groups, and place it between green and violet. These cultural, gender and ethnic variations are as fascinating as they are hard to explain. ${ }^{55}$

Sometimes, different people respond to colors in a variety of ways. For examples a city dweller might hate gray because it is associated with rain, and when the weather is gray they can't walk around town, its harder to get a taxi and they smell of rain. A farmer, on the other hand, might love it. The gray is a welcome change from the harsh sunlight and the rain breathes life into his crops and nature. Similarly, people may bring different associations to the same colors. One person may think of green as positive, associating it with nature and growth; another, however, may think of it negatively, like

\footnotetext{
${ }^{55}$ Birren 65.
} 
mold, mucus or a lime green track suit. While looking at the selected paintings the children should be encouraged to express how each color makes them feel and to explore why there might be differences.

Many people, especially children, are eager to talk about their favorite colors. During this portion of the tour, it could be productive to ask everyone's favorite color. When at an artwork with a prominent amount of that color, have them discuss what the color conveys and how it makes them feel, in that particular work. This open-ended exercise will help them understand how and why their favorite color is used by an artist, and it may even cause them to realize why they have their favorite color.

\section{$\underline{\text { Red and White }}$}

Merry Joseph Blondel's piece, Portrait of Madame Houbigant ${ }^{56}$, displays excellent examples of not just the use of one principle color, but two. The white and the red cloths in the painting are pure and vibrant. Each color carries emotion and meaning quite clearly. The white operates as a symbol of purity, cleanliness and daintiness. These three things would have been qualities of the utmost importance for a lady to have at the time. This is probably the reason she wished to be portrayed in the white garment.

The red serves as an interesting foil to the white. It is the color of excitement and raw emotion. Red is possibly the most emotionally charged color. It has many different associations however. For example, red is used quite frequently in national flags, but the meaning or idea represented by the color on each individual flag is unique. It ranges from war and blood to bravery, authority to fire, unity to revolution, soil to sacrifice, faith to the sun, freedom to revolt, swordsmanship and horsemanship to independence, law and authority to brotherhood and equality, nation to charity, vitality and friendliness to

\footnotetext{
${ }^{56}$ Figure 14
} 
warmth. ${ }^{57}$ In each case it is a powerful and important color, but the specific meaning varies.

According to The Mary Gilliatt Book of Color" 58 , red is the "emboldening, stirring: the red badge of courage, the dashing Scarlet Pimpernel, the flag of martyrs and of revolutionaries, the colour of danger and of sin." This is perhaps to counteract the plainness of the white, but the color of lust and other unbecoming emotions is not on the person of the woman. She is separated from it. The white and red form a dichotomy of worlds. One (white) which is pristine and elitist, which she is a part of, and another (red) which is full for raw emotions unbecoming a gentlewoman.

\section{$\underline{\text { Yellow and Gold }}$}

Frank Stella's Chocorua $I^{59}$ has an immediate effect. Its shockingly bright fluorescent yellow startles the viewer immediately. Conversely, John Singer Sargent's Interior of Santa Sophia ${ }^{60}$ is filled with soothing Gold tones, which help to convey the religious mood. Although both paintings have a strong yellow base the overall feeling is almost completely opposite. Stella's is bright and energetic, while Sargent's is calming and awe-inspiring. If the viewers compared the two they would probably chalk the difference up to the color difference, but in reality yellow and gold are no more different than red and pink or navy and cyan. Different shades, intensities and materials can affect the mood and artists have to make countless decisions to convey the one they want.

Gilliant says of yellow "Yellow is the colour of sunlight, gold, sandy beaches, spring flowers and the dazzle of buttercups and dandelions in summer meadows . . . It is

\footnotetext{
${ }^{57}$ Gage, Color in Art 153.

${ }^{58}$ Gilliatt 58.

${ }^{59}$ Figure 15

${ }^{60}$ Figure 16
} 
associated with brightness and cheerfulness, warmth and sparkle." When considering this interpretation of the color the similarities between the two paintings become more clear. They both convey light, warmth and sparkle, but in different ways. This gives the viewers a chance to consider how colors can consistently convey certain moods or themes, no matter how they are contextualized.

\section{Green}

Reclining Figure ${ }^{6 t}$ by Henri Moore is an interesting sculpture when one is considering color. Sculptures, in general, usually focus more on form then color, and therefore usually have much less to them when it comes to conceptual color. The color of this piece, however, drastically changes how it can be viewed. One of the things which is most often said about it is that it looks like a landscape. People say this even though it is very obviously a humanoid form. The color of the work, however, alludes to nature and turns the person into rolling hills. If it were copper colored or bright magenta many fewer people would probably associate it with a landscape. The color suggests to us something we readily know and so we interpret it as such.

\section{Black and Blue}

Black is one of the most emotionally charged colors. Death, despair and sadness exude from it. In artwork there is no difference. In Landscape with a Mill with a View of Montmartre $e^{62}$ by Georges Michel we see these intense kinds of emotions come through. The dreary, dark landscape has a feeling of desolation and hopelessness. Because the colors are so obviously not naturalistic, the students will have to discuss why the artist chose to use so much black in the painting.

\footnotetext{
${ }^{61}$ Figure 17

${ }^{62}$ Figure 18
} 
A color doesn't always have to be overwhelming to have an effect on an artwork's mood. For example the blue in Francis Cotes's painting Double Portrait ${ }^{6.3}$ is confined to the background. In all it probably takes up around a third of the works surface, but it sets the mood and is what your eye focuses on. The cool blue gives a sense of comfort and relaxation. Perhaps the blue is so noticeable because of the subdued colors in the rest of the painting. It is completely white or very light. This gives the cool tone the chance to set the mood for the entire work.

Blue is a color which is particularly significant to the portrayal of emotion in art. While talking about this work and color I would also bring up Picasso's Blue Period. ${ }^{64}$ This period in Picasso's art and work occurred between 1901 and 1904, and it reflects a low point in the artist's life. ${ }^{65}$ His best friend, Casagemas, killed himself and Picasso found himself alone. The works portrays a sadness and loneliness that is unmistakable. The sadness of this period also caused Picasso to move from classicism to more abstract art.

In Waiting for the Ferry at the Falcon Tavern ${ }^{66}$, we see an interesting example of how black and blue work together. The painting as a whole is almost monochromatic. Blacks and grays overwhelm, such as in the colors of the landscape, buildings, water and the adults' clothes. These somber colors give the painting a slightly sad, yet formal feeling. If white represents innocence, then black represents defilement. The only significant glint of color we see is in the little girl's dress. A bright, beautiful blue replaces the black of her parents' clothes. Blue becomes a symbol of hope and youth,

\footnotetext{
${ }^{63}$ Figure 19

${ }^{64}$ Top-Tour-Of-Spain

${ }^{65}$ Blue period, between classicism and abstract art.

${ }^{66}$ Figure 20
} 
setting her apart from the gray world around her, showing that color's meaning changes with context.

\section{Black and White and Grayscale}

Sometimes lack of color can be equally as effective as the color schemes looked at so far. For this reason I have included examples of black and white and grayscale. Although these pieces are not filled with rich vibrant colors, the lack of colors can affect the mood in a powerful way. The works become more somber and serious, in some cases scary and depressing. With these pieces, the tour leader can discuss concepts like "why do you think the artists chose to leave out color?" Discussing the lack of color in artwork can help some understand color even more.

Albrecht Durer's print Saint Eustace ${ }^{67}$ is in black ink on white paper. This simplifies the work and puts attention on line and contrast, but what else does it accomplish? If the print was colored, the feeling, meaning and style of it would be altered greatly. The key to this work is to understand the role of color by analyzing a work devoid of it.

Woman in the Studio (Jacqueline Roque ${ }^{68}$ ) by Pablo Picasso is a particularly fascinating example of grayscale, because the painting itself is mostly neutral and lacking of much color, but there is a painting within the painting in which there is color. This gives us the opportunity to compare grayscale to color in one work. The relationship between the color and the gray creates an interesting dialogue that can be explored by children as well as more experienced learners.

\footnotetext{
${ }^{67}$ Figure 21
}

${ }^{68}$ Figure 22 
The last two works, especially the latter, can also be used to teach value. Value is the proportion of light or dark in the color. The simple black, white and grays present value it its simplest form. The human eye can easily differentiate and name five independent values between black and white: black and white themselves, on either end, middle gray, directly in the middle, which is the most unassuming and comfortable of colors, dark gray, between black and middle gray and finally, light gray, between white and middle gray. ${ }^{69}$ Art students can subdivide these shades of gray, or value almost infinitely, but these subtle variations often require close proximity to differentiate.

\section{Giving the Tour}

Each art work is a complex specimen of color theory. Many can serve to teach a variety of principles. For example, while The Peach is listed here in warm colors, it would also do well for teaching complementary colors. Double Portrait is suggested to teach the effects of blue, but it also has complementary colors. The flexibility in use of the artworks serves many purposes: 1) Not all artworks are always on view; if Interior of a Kitchen is gone for some reason, it is still important to teach primary colors. 2) A short tour may only encompass 4-6 works, but it is possible to discuss more than 4-6 concepts. 3) A docent might feel more comfortable discussing the effects of blue with Waiting, and therefore could use this painting, instead of the suggested example.

Before giving the tour docents, or other leader, should ask some fundamental questions of the group to see where they are. If they aren't even sure whether or not red is a primary color the tour will definitely have to be adjusted. Similarly, if they can name all primary and secondary, warm and cool and complementary colors without much hesitation, the docent will have to spend far less time explaining the fundamentals.

\footnotetext{
${ }^{69}$ Sargent 11.
} 
A tool that is vital for this tour is a proper color wheel. The wheel itself will be pretty standard (three primaries, three secondaries and six tertiaries), the unique thing about the color wheels will be three clock-hand like dials which can be moved around to show concepts like triads, analogous colors, complementaries, and so on. This will make the concepts more concrete and demonstratable.

\section{Activities}

The tour itself and the activities are designed to be fun. Museum education should always focus on fun. Without a feeling of comfort, approachability and fun, visitors will associate negative feelings and experiences with the museum, and will not return in the future. One game that I feel will really get kids thinking about color is the old classic designed by Joesf Albers himself, and described earlier. ${ }^{70}$ One takes a square of color and places it on two different larger squares of varied color. The original color will look different juxtaposed against the larger color field. For example, a gray square will look orangeish in a blue square and vice versa.

Another successful activity is proposed in Color: A Complete Guide for Artists. ${ }^{71}$ Take a solid colored background (a sheet of construction paper works best), in three colors: red, yellow and green. Than take three pieces of fruit, each a bright and saturated color: a red apple, a yellow banana and a green pear. Place each of the pieces of fruit on each of the papers and note the effect. When on the sheet of their own color they are barely noticeable and unattractive. When we place the red and green fruits on the green and red papers, respectively (their complementary), they jump out and have a high contrast. Sticking the apple or the pear on the yellow sheet and the banana on the red or

\footnotetext{
${ }^{70}$ Albers

${ }^{71}$ Fabri 34.
} 
green sheet provides the most attractive look, with the fruits looking bright and appealing.

When one stares at a color for an extended period, the eyes become wary of that color. For example, if you were to stare at red the red cones would become temporarily dulled. Than, when you look away, the other cones compensate. So although you are looking at a white wall, you see a slightly green color in the same shape as the red. ${ }^{72}$ In the tour, I will use an exercise similar to this to convey the concept of complementary colors. It is a fascinating and hands on activity which hopefully will make the visitors be more involved, entertained and receptive.

These exercises will hopefully open up the children's eyes about the complexities of color. They are hands on, open ended and require critical thinking. Hopefully, they will also function as a way to make art more accessible and help them feel more confident about discussing and exploring art.

\section{Brochure/Pamphlet}

Although designed as a formal, docent led tour, "Exploring Color in Art" can easily be adapted in a brochure/pamphlet format. This would make it accessible to visitors beyond school groups. It could be useful for families with school age children or adults who would like to learn more about color.

The brochure could include instructions on which artworks to view and what to look for in each one. The discussion questions along with suggested, possible answers could also be included, in order to get the visitor thinking about ideas and concepts they wouldn't otherwise. Color wheels could be included in gallery kits, that families can check out while visiting the Speed. Finally, activities such as Alber's optical illusions and

\footnotetext{
${ }^{72}$ Sargent 116.
} 
the after-image exercise can be included to bring the hands-on portion of the tour to life as well.

\section{Practical Application and Evaluation}

In order to test my tour, and make necessary changes, I gave it to a fourth grade class myself. This allowed for me to see, first hand, what worked, what didn't and what could work, if done differently. I was pleasantly surprised that no major changes were needed, however I did learn a lot from the experience.

I worked with Mrs. McAvinue's fourth grade class from McFerran Preparatory Academy. Kim Mattingly was the assisting art teacher. Before giving the tour, I met with the class three times, in order to acquaint students with some color vocabulary. The very first thing I did was give a pre-test. ${ }^{73}$ The questions were deliberately challenging, because my aim was to show the tour would lead to an improvement in scores, by the students. The initial test results were somewhat disappointing. The class average was 2.96 out of 10 with the scores ranging from 1 to 6 out of 10 . Many of the students expressed frustration with the vocabulary on the pre-test, not knowing what many words or phrases meant. I looked at this as a learning opportunity and hoped that they would be more comfortable with these when taking the post-tour test.

During the classroom visits I did two of the tour's recommended activities with the children. This worked fabulously; during a tour there is rarely enough time, nor a suitable working space to do such activities, so doing them in a classroom setting was much more feasible. The children did the fruit and negative image exercises, and I referred to these exercises during the tour.

\footnotetext{
${ }^{73}$ See Appendix
} 
Instead of using actual fruit, I had them draw and color an apple, a pear and a banana. They then could glue their fruit to the various backgrounds and identify the color scheme. We covered complementary and analogous color schemes, and I went on individually to monochromatic with students who seemed to grasp the other concepts. The kids labeled their arrangements and were able to take them home.

The negative image activity was a little confusing to the kids at first. I had them color a landscape in colors which are complementary to the natural colors (i.e. a purple sun, red grass, an orange sky, etc.) and then do the staring experiment. At first the kids were very upset and confused as to why they had to use the wrong colors. I continued to tell them that there was a very rewarding end. When they saw the after-image they were very excited. Although, not all the children were able to see an after-image, the majority of them did and there was a very important "wow!" learning moment.

The day of the tour was very rewarding. Although, I had to make many impromptu changes as I was giving the tour, the children stayed engaged and interested. They also asked a lot of questions. I had the group of 23 for just over an hour, and we saw eleven of the artworks mentioned in my tour.

We started in the sculpture court and looked at the Henri Moore (Reclining Figure) and the Marc Chagall (Waiting). We then went through the African gallery and looked at the Shinobare (Three Graces) and the Yaruba Doors. Immediately, the kids were engaged asking many questions, making comparisons and using new vocabulary we had learned.

Upstairs we looked at The Interior of a Kitchen, Interior of Santa Sophia, Landscape wit a Mill with a View of Montmarte, Waiting for the Ferry at the falcon 
Tavern and Gray Weather. The children continued to be responsive and interested. The best moment of the entire tour happened while we were looking at The Interior of a Kitchen. When I asked what color scheme was present, around half the class shouted out "primary color triad." On the first day I was with them I used the word triad and they looked at me like I was speaking in Japanese. They had a hard time understanding what it was, and what color schemes were or were not color triads. It was very rewarding to see that they had learned something new, and could articulate it when discussing art.

Finally, downstairs we looked at William Mason Brown's two fruit pieces: Raspberries and Peaches. I related these artworks to the fruit project they did. They identified the color of the fruit, the color of the background and finally what color scheme it was. After deciding the pieces were complimentary and analogous, respectively, they identified how each color scheme functions. Complimentary colors make each other pop out, while an analogous color scheme is harmonious.

At the end of the tour I felt confident that the children had both utilized what I taught them in class, as well as learned more from the tour. The class and teachers said they had lots of fun. The only thing left to do was the post-test.

The post-tour test was indeed successful. There was a significant change in the class average, from 2.96 , up to 5.78 . Once again, I deliberately made the test challenging to really test what the kids knew. In retrospect I would have made it slightly easier, for less frustration, but there was still an impressive outcome. The class scores ranged from 2 out of 10 to 8 out of 10 , which was also an improvement since the pre-test.

Only three children didn't improve their score; one of these kept a 6 out of 6 . The students who spoke English as a second language improved greatly, with an increase 
ranging from 4 to 5 points. This is probably due to their introduction to a variety of new color terms, which were not in their vocabulary before.

The most significant change was from 1 out of 10 , to 8 . One went from the lowest score, to the highest. During the tour he was very attentive and involved, and asked many questions. This shows that motivated students can learn a great deal from my tour, and using color to engage is an effective motivator.

On the post-test the kids had an opportunity to write about something new, they learned about color. The most common responses regarded learning new vocabulary words like color triad, analogous colors, complementary colors and monochromatic. They also learned concepts like when there is a lack of color the artist is focusing on something else, certain colors make other colors stand out and that colors convey emotions. These analysis and critical thinking skills are at a higher level of achievement and proficiency, that are Kentucky education goals.

The kids learned a lot, and both they and I had a lot of fun. At times it was somewhat frustrating, but that the end product was successful. The tour successfully introduced students to multiple concepts, vocabulary and examples of color in art and motivated them to want to learn more. I feel like it was a great success.

\section{Conclusion}

The activities and discussions designed for this tour, developed in conjunction with the overall enjoyable subject of color, provide positive experiences and with its fun enjoyable approach will successfully build regular visitors to the museum. The tour itself teaches both specific core content related to color, and encourages critical thinking. The tour is multi-disciplinary, as it touches on the historical, cultural, scientific, 
psychological, physiological and linguistic aspects of color. My tour will benefit not only the Speed and its visitors, but it will bring a higher consciousness about color and color theory to the community. 


\section{REFERENCES}

Albers, Josef. Interaction of Color. New Haven and London: Yale University, 1963.

Batchelor, David. Chromophobia. London: Reaktion Books Ltd, 2000.

Batchelor, David. Colour. London and Cambridge: Whitechapel and MIT Press, 2008.

Birren, Faber. Color and Human Response. New York: Van Nostrand Reinhold, 1978.

Blue period, between classicism and abstract art. Paintings.name webmaster. November 14, 2006. <Pablo-picasso.paintings.name/blue-period>

Burton, Hanly, Robert A. Fellenz, Laura Gittings-Carlson, Janet Lewis-Mahony, Bonnie Sachatello-Sawyer and Walter Woolbaugh. Adult Museum Programs. Walnut Creek, CA: AltaMira Press, 2002.

DeMarco, Dr. Paul J. Personal Interview. 13 November 2008.

Fabri, Ralph. Color: A Complete Guide for Artists. New York: Watson-Guptill Publications, 1967.

Fehr, Michael and Wurmfeld, Sanford. Seeing Red. Cologne: Salon Verlag, 2004.

Fisher, Mary Pat and Paul Zelanski. Color: Fourth Edition. Upper Saddle River, NJ: Prentice Hall Inc., 2003.

Gage, John. Color and Culture. Singapore: Bulfinch Press, 1993. pgs. 79-80.

Gage, John. Color in Art. London: Thames and Hudson Ltd., 2006.

Gilliatt, Mary. The Mary Gilliatt Book of Color. Boston: Little, Brown and company, 1985.

Golden, Mark. Tradition and Colors. Klaus Stromer, 2000.

Graphic Design. 2002. Bloosburg University Virtual Training Help Center. November 1, $2006<$ iit.bloomu.edu/vthc/Design/psychology.htm> 
Guptill, Arthur L., Color Manual for Artists. New York: Van Nostrand Reinhold Company Inc., 1962

Itten, Johannes, The Art of Color. New York: Reinhold Publishing Corporation, 1961.

Kandinsky, Wassily "Concerning the Spiritual in Art", Art in Theory 1900-2000. Editors: Charles Harrison and Paul Wood. Malden Massachusetts: Blackwell Publishing, 2002.

Kay, Paul and Maffi Luisa. "Color Appearance and the Emergence and Evolution of Basic Color Lexicons.” American Anthropologist. December 1999: pp. 743-760.

Kentucky Department of Education Core Content for Arts and Humanities Assessment Version 4.1

Kentucky Department of Education Core Content for Science Assessment Version 4.1

Livingstone, Margaret, Vision and Art: The Biology of Seeing. New York: Harry N. Abrams, Incorporated, 2002.

Matthaei, Rupprecht. Goethe's Color Theory. New York: Van Nostrand Reinhold Company, 1970.

Pigments Through the Ages. Institute for Dynamic Educational Advancement. November 9, 2006. <webexhibits.org/pigments/indiv/color/blues4.html>

Rompilla, Ethel. Color for Interior Design. New York: Harry N. Abrams, Inc., Publishers 2005

Sargent, Walter. The Enjoyment and Use of Color. New York: Charles Scribner's Sons, 1923.

Top-Tour-Of-Spain, The Renowned Pablo Picasso Blue Period. November 14, 2006. $<w w w$.top-tour-of-spain.com/Picasso-blue-period.html >

Wattenwyl, Andre Von and Zollinger, Heinrich. "Color-Term Salience and Neurophysiology of Color Vision." American Anthropogist. June 1979: pp. 279-288. 

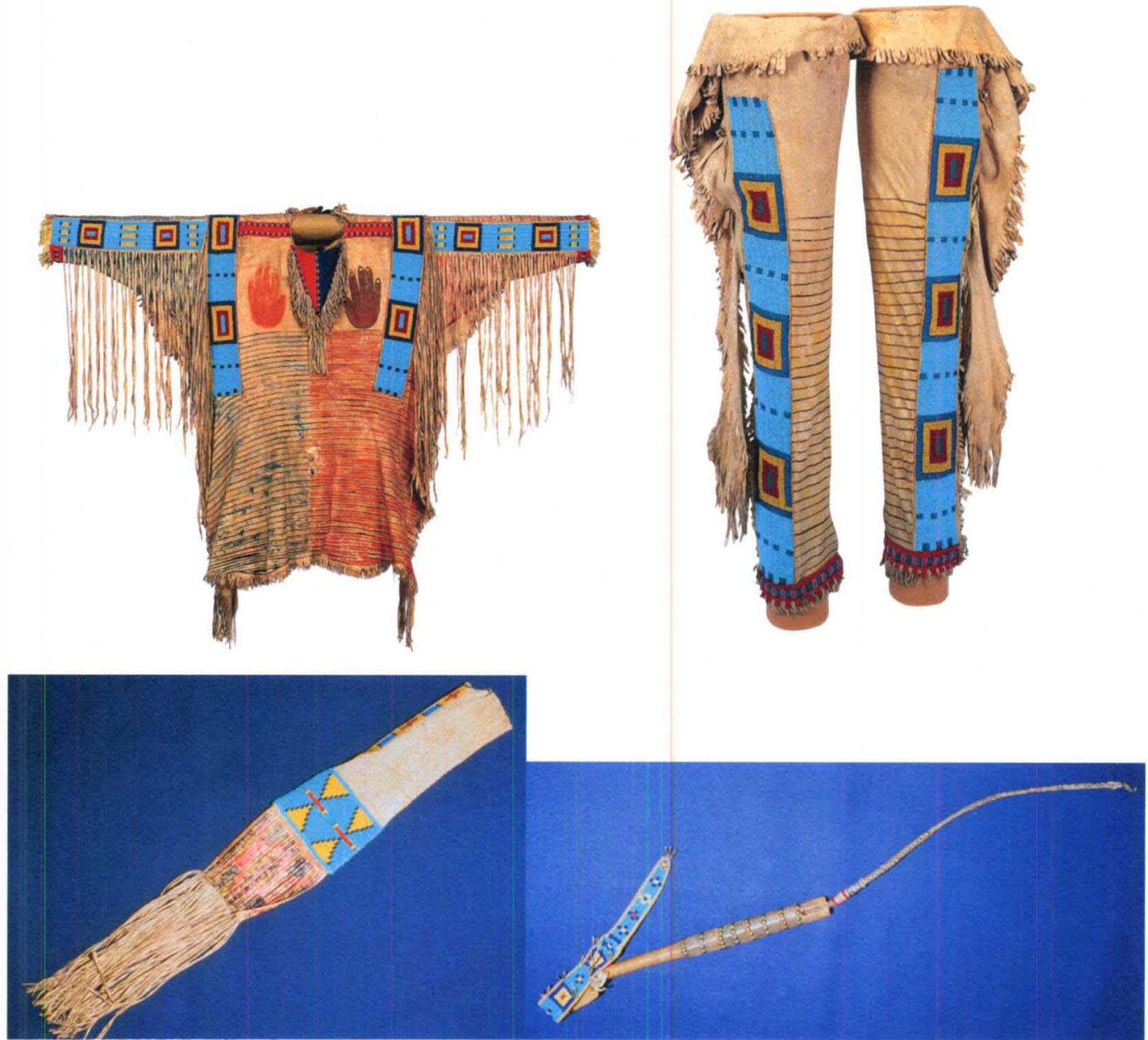

Figure 1

Lakota Sioux, Northern Plains

Quiver and Bow Case with Arrows, War shirt, and Quirt, about 1873

Tanned Deer Hide, pigments, glass beads, wool cloth

Museum Purchase 1937.68 


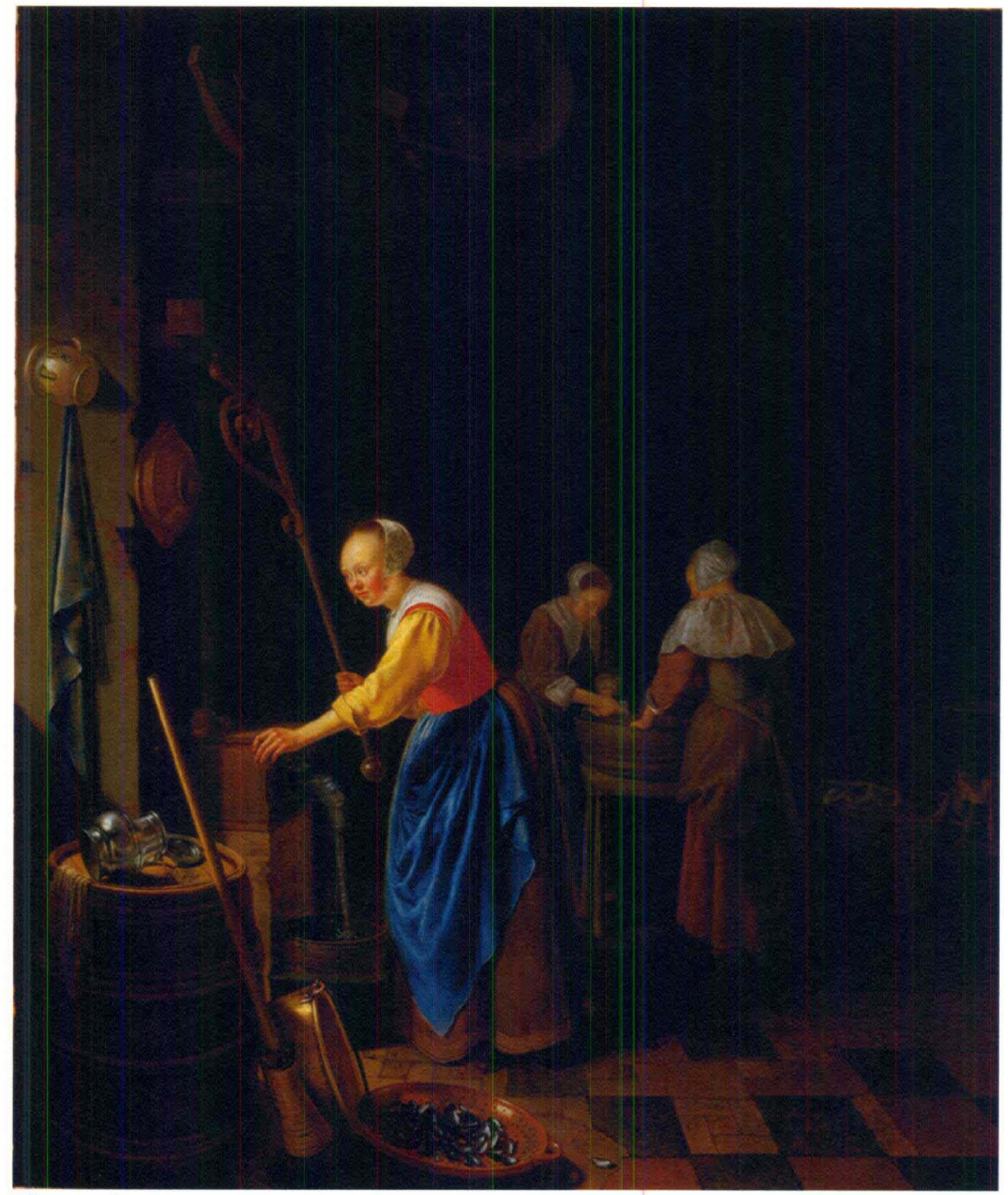

Figure 2

Pieter Cornelisz. van Slingeland

Dutch, 1640-1691

The Interior of a Kitchen, about 1658

Oil on panel

$175 \% 16 \times 14 \%$ in

Gift of the Charter Collectors and Mrs. Blakemore Wheeler, Mr. And Mrs. Barry Bingham, Sr., Mrs. Hattie Bishop Speed Mrs. E. Gary Sutcliffe, Mrs. Margaret Bridwell, Mrs. Oscar Fenley, and Mr. And Mrs. Klaus G. Perls, by exchange 1992.23 


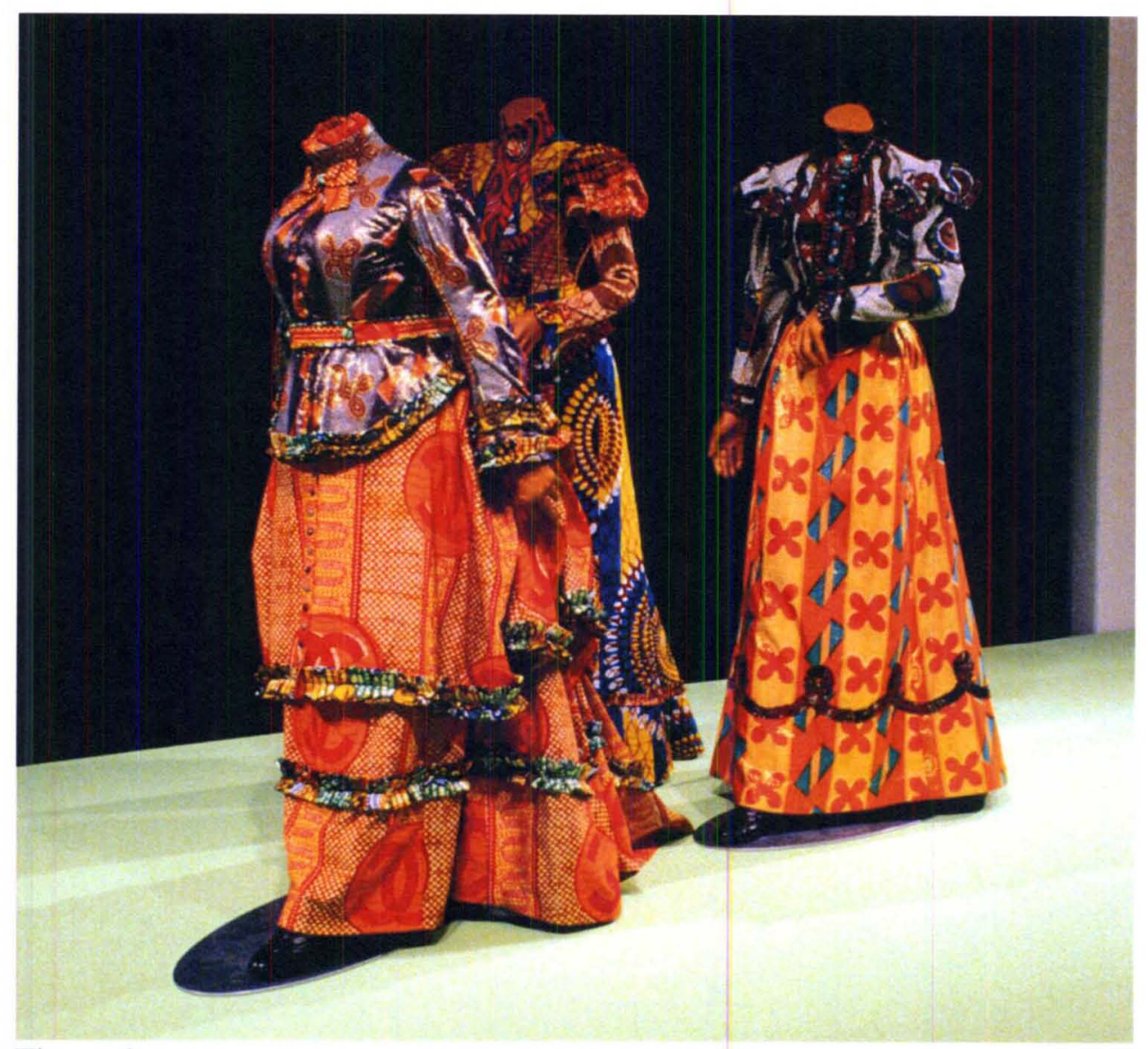

Figure 3

Yinka Shonibare, MBE

British, born 1962

Three Graces, 2001

Printed cotton textile, three fiberglass mannequins, three aluminum bases Life-size

Purchased with funds from the Alice Speed Stoll Accessions Trust 2002.6 a-c 


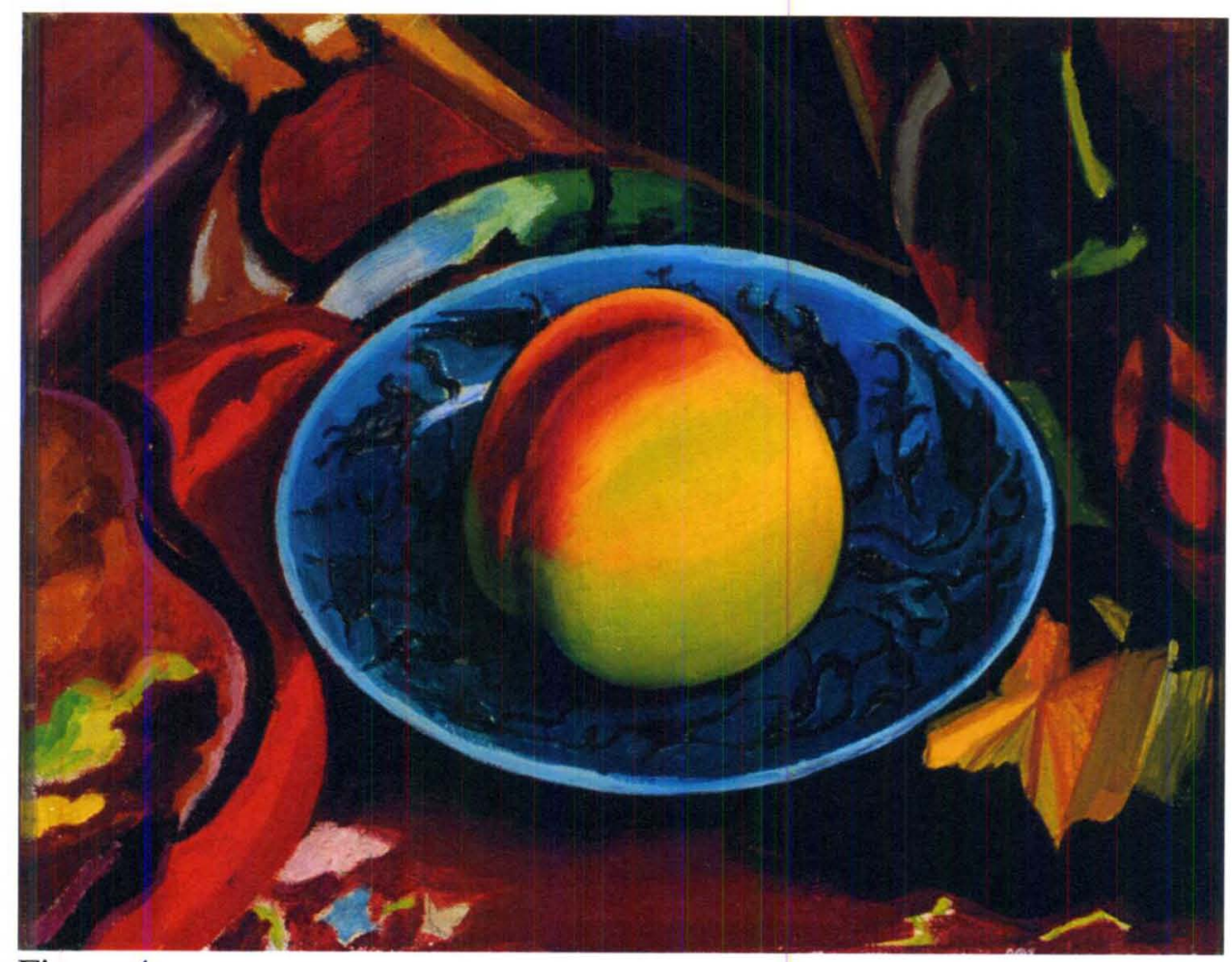

Figure 4

Joseph Stella

American, 1877-1946

The Peach, about 1929

Oil on Canvas

$11 \times 14$ in.

Partial and Promised gift, anonymous Louisville collection 2006.7.4 


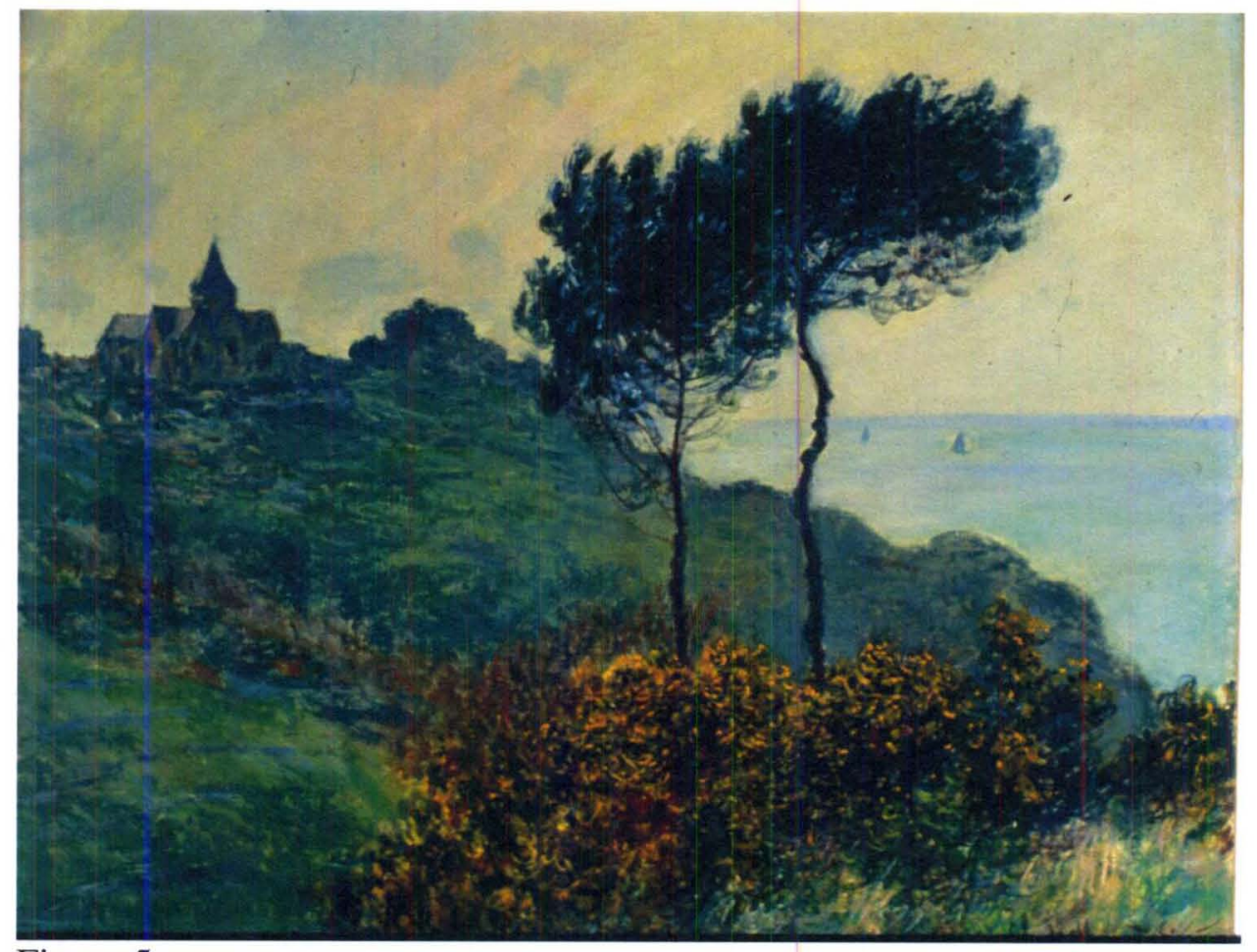

Figure 5

Claude Monet

French, 1840-1926

The Church at Varengeville, Grey Weather, 1882 Oil on Canvas

$25 \frac{5}{8} \times 32$ in.

Bequest of Mrs. Blakemore Wheeler 1964.31.20 


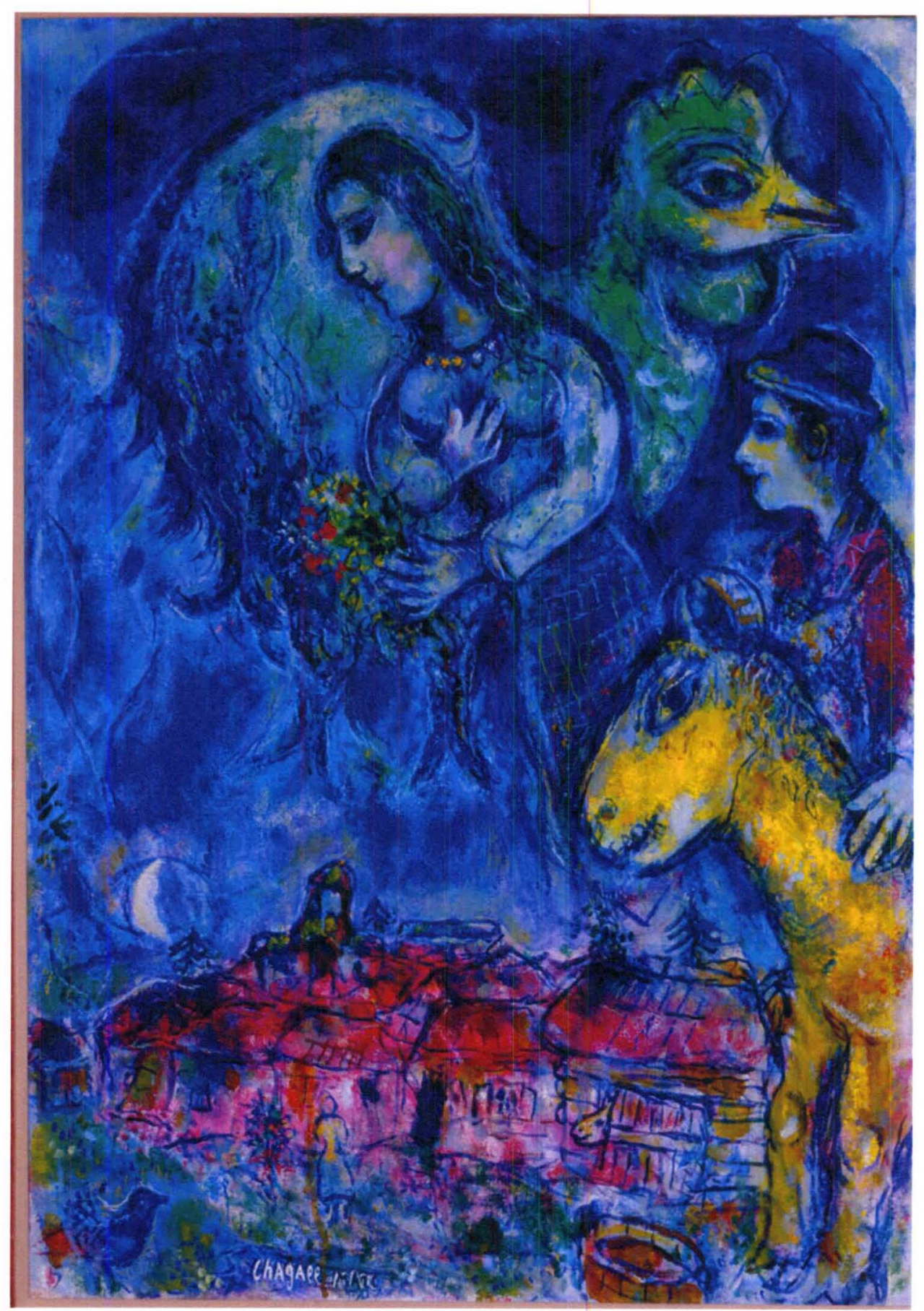

Figure 6

Marc Chagall

French, born Belorussia, 1887-1985

Waiting (L'Attente), 1967

Oil on canvas

$36 \frac{3}{8} \times 25 \frac{5}{8}$ in.

Bequest from the Nancy Batson Rash and Dillman A. Rash Collection 1998.19.1 


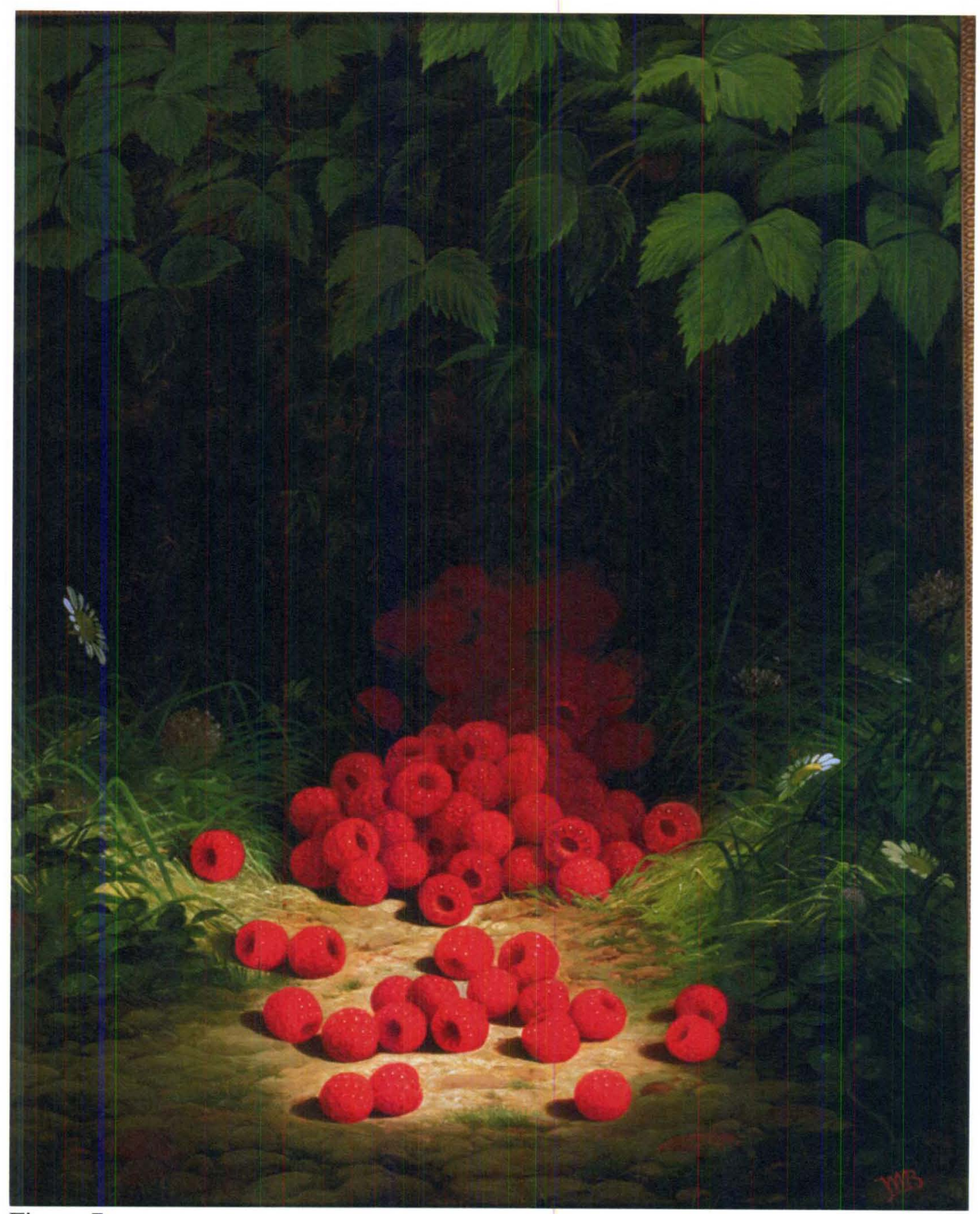

Figure 7

William Mason Brown

American, 1828-1898

Raspberries, about 1870

Oil on canvas

$20 \frac{1}{8} \times 16^{3 / 16}$ in.

Gift of Mrs. Hattie Bishop Speed

1927.29 


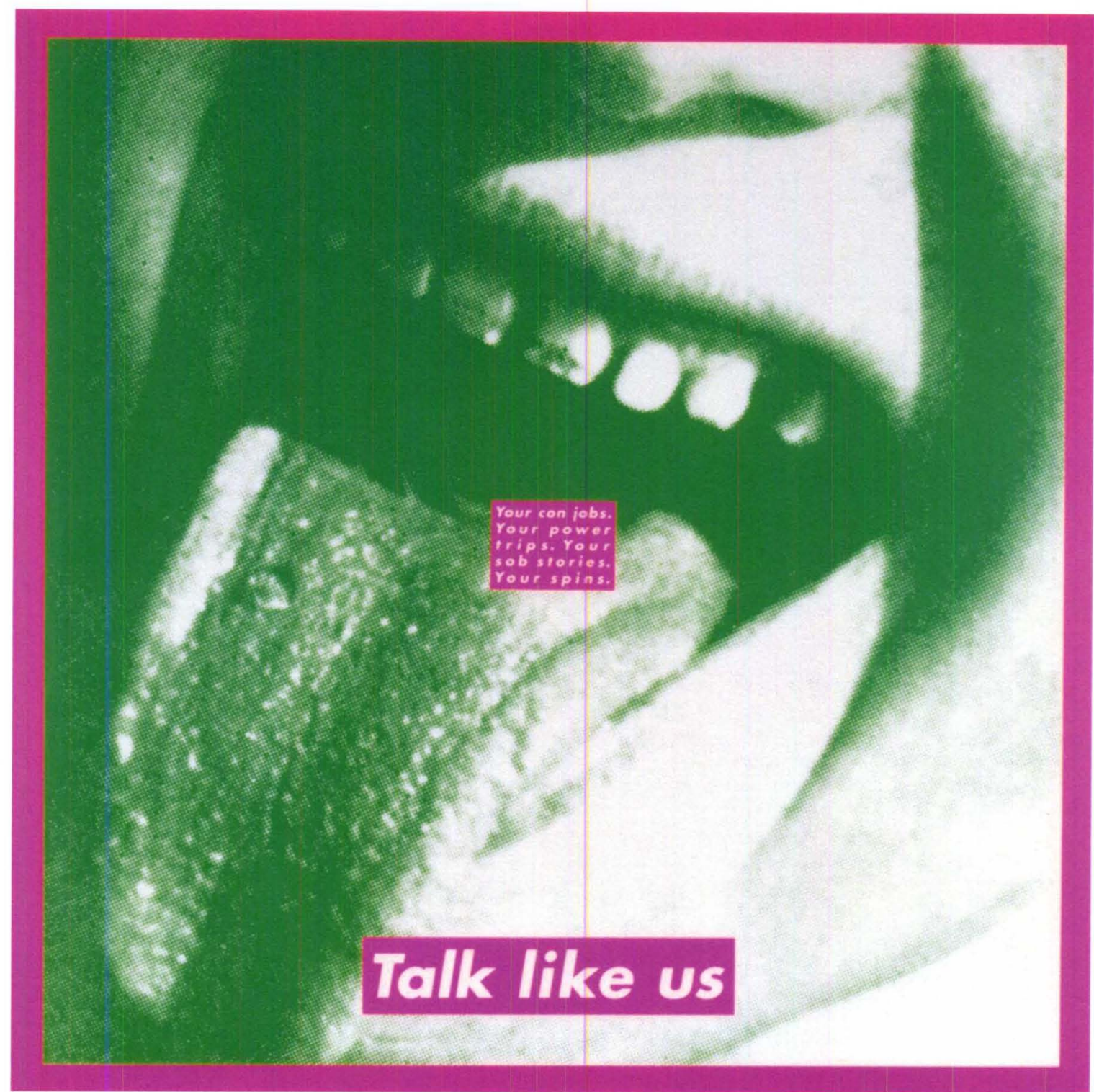

Figure 8

Barbara Kruger

American, born 1945

Untitled (Talk Like Us), 1994

Photographic screenprint on Plexiglass

$55 \times 55$ in.

Gift of Mrs. Hattie Bishop Speed, by exchange 1994.3.2 


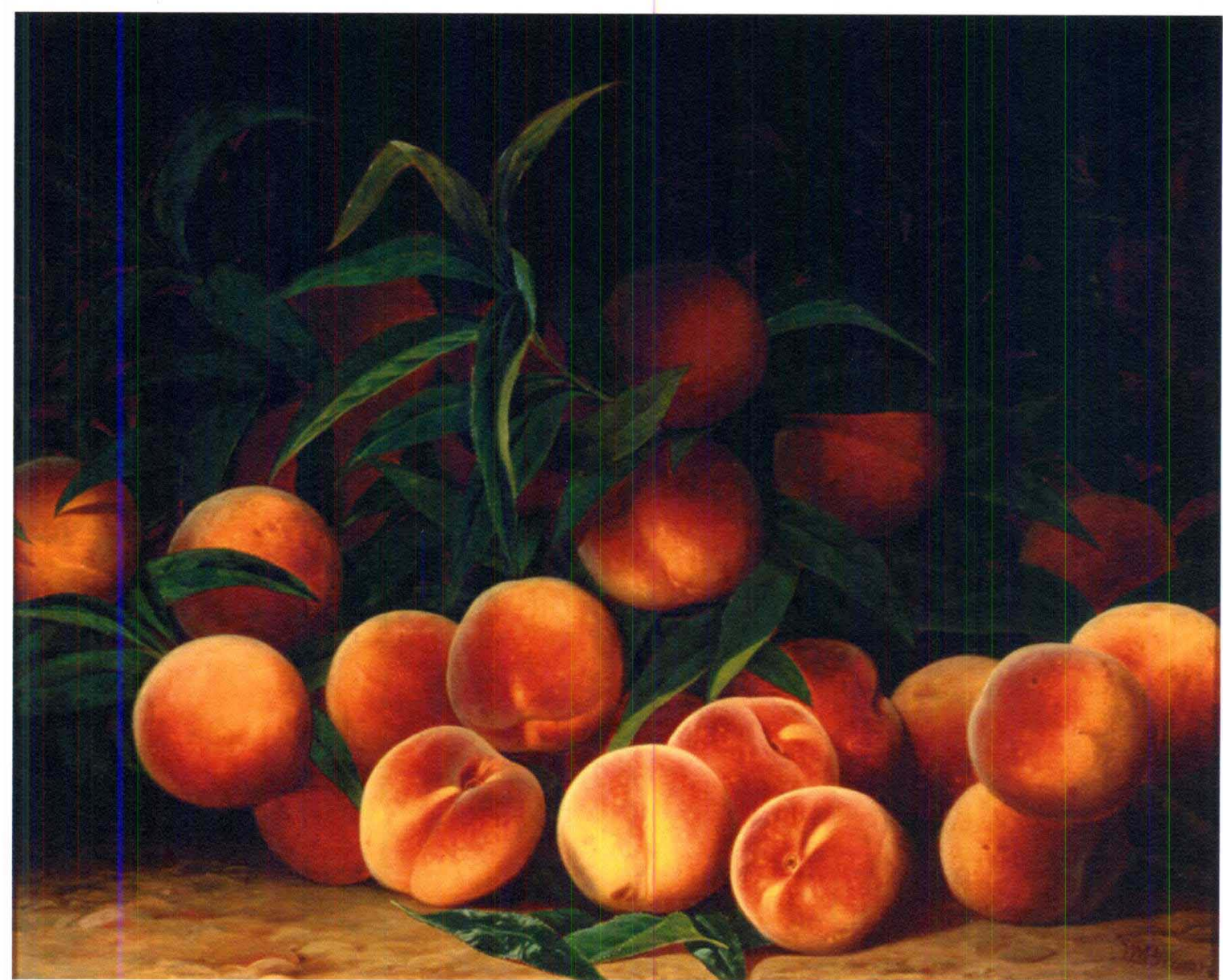

Figure 9

William Mason Brown

American, 1828-1898

Peaches, about 1870

Oil on canvas

$161 / 4$ x 20 in. $(41.3 \times 50.8 \mathrm{~cm}$.

Gift of Mrs. Hattie Bishop Speed

1927.28 


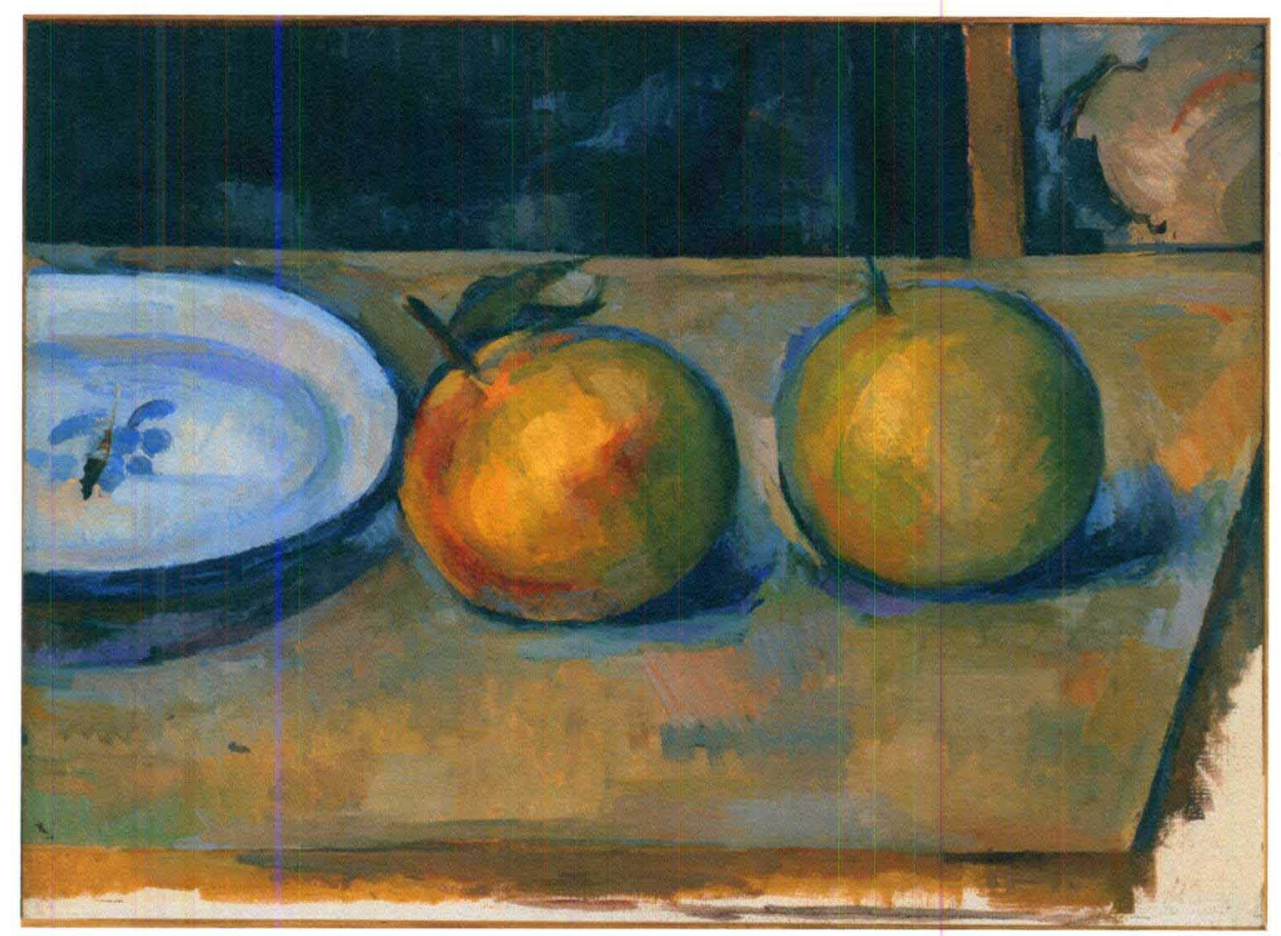

Figure 10

Paul Cézanne

French, 1839-1906

Two Apples on a Table, about 1895-1900

Oil on Canvas

$9^{1 / 2} \times 13^{1 / 16}$ in.

Purchased with funds from the Alice Speed Stoll Accessions Trust and with funds donated by Wayne Perkey and Family, Mrs. W.L. Lyons Brown, Mrs. Harry S. Frazier, Jr., Sandra A. Frazier, Mr. And Mrs. Randall B. Hocknsmith, The University of Loiusville Foundation, Inc., Dr. and Mrs. Condict Moore, Helen Condon Powell, and Mr. And Mrs. Edmund A. Stienbeck, Jr.

2000.21 


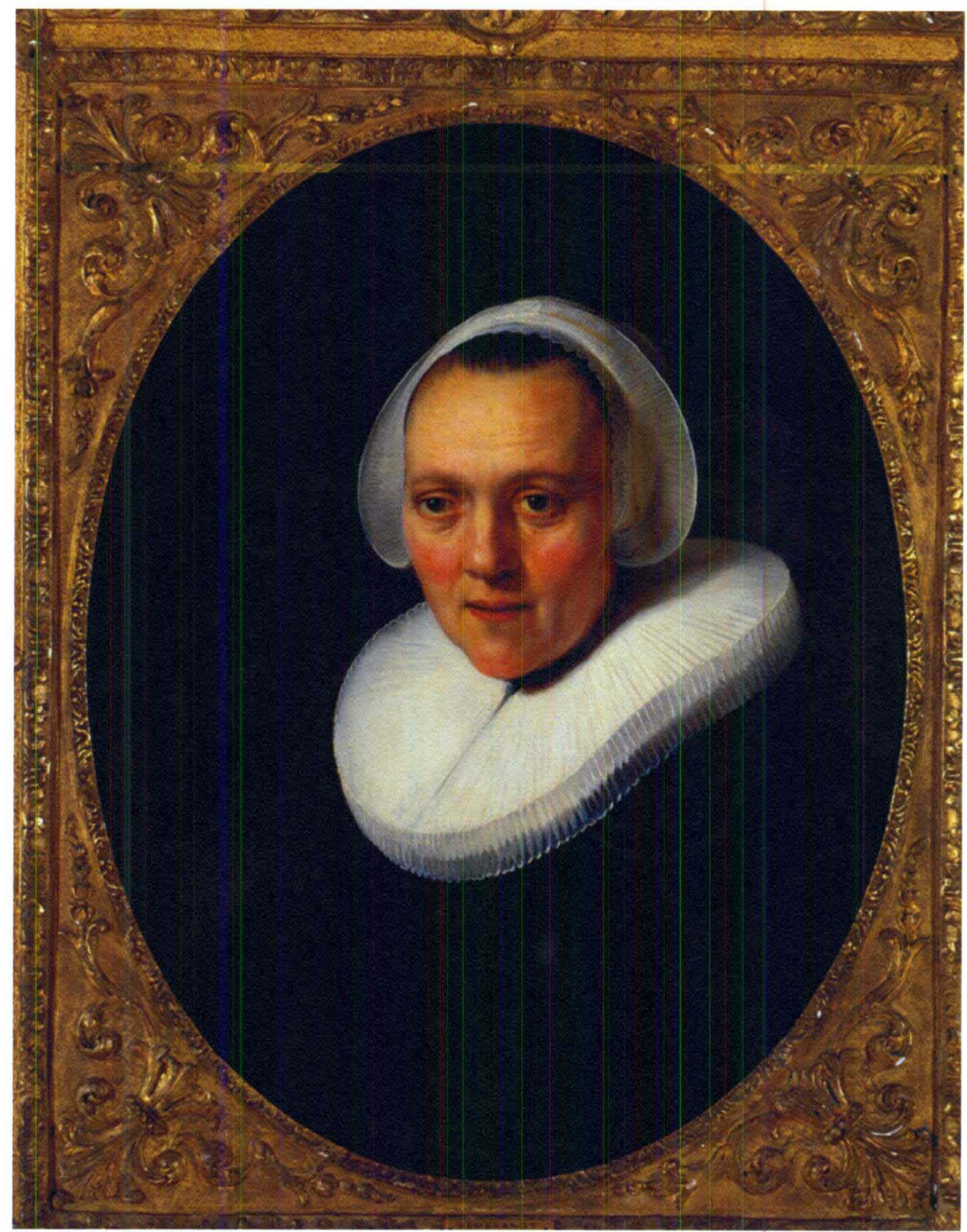

Figure 11

Rembrandt van Rijn

Dutch, 1606-1669

Portrait of a Forty-Year-Old Woman, possibly Marretje Cornelisdr. van Grotewal, 1634 Oil on Panel

$27^{7} / 16 \times 22$ in

Purchased with funds contributed by invividuals, corporations, and the entire communiy of Louisville, as well as the Commonwealth of Kentucky 1977.16 


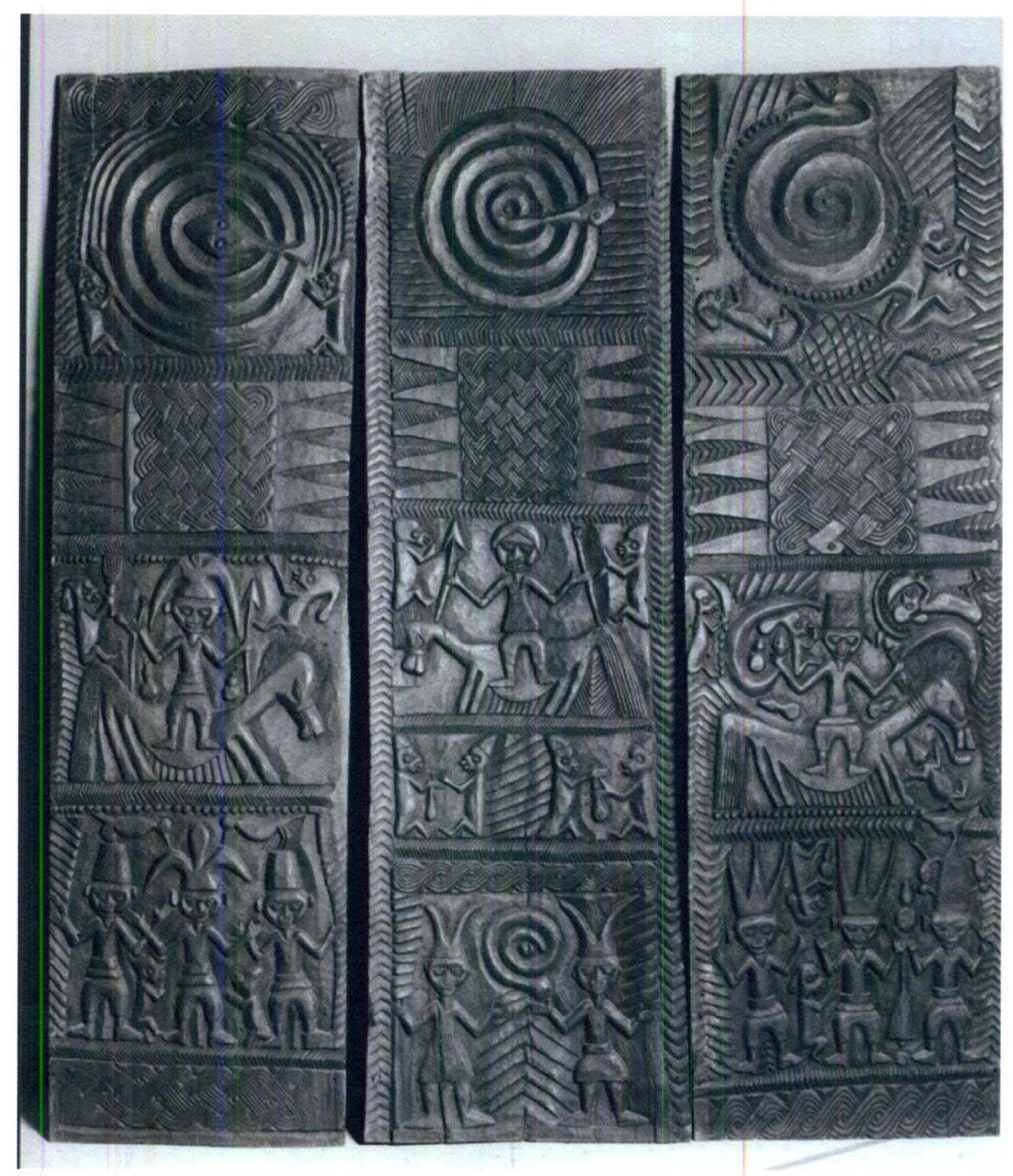

Figure 12

Yoruba people, Nigeria, Ijebu-Ode Panels, late $19^{\text {th }}$ century

Wood

Left: $70 \times 19^{7} / 8 \times 21 / 2$ in.

Center: $701 / 8 \times 21 \frac{1}{8} \times 2 \frac{7}{8}$ in.

Right: $701 / 4 \times 21 \frac{1}{8} \times 2 \frac{7}{8}$ in.

Gift of Mrs. William B. Belknap

1976.12.1-3 


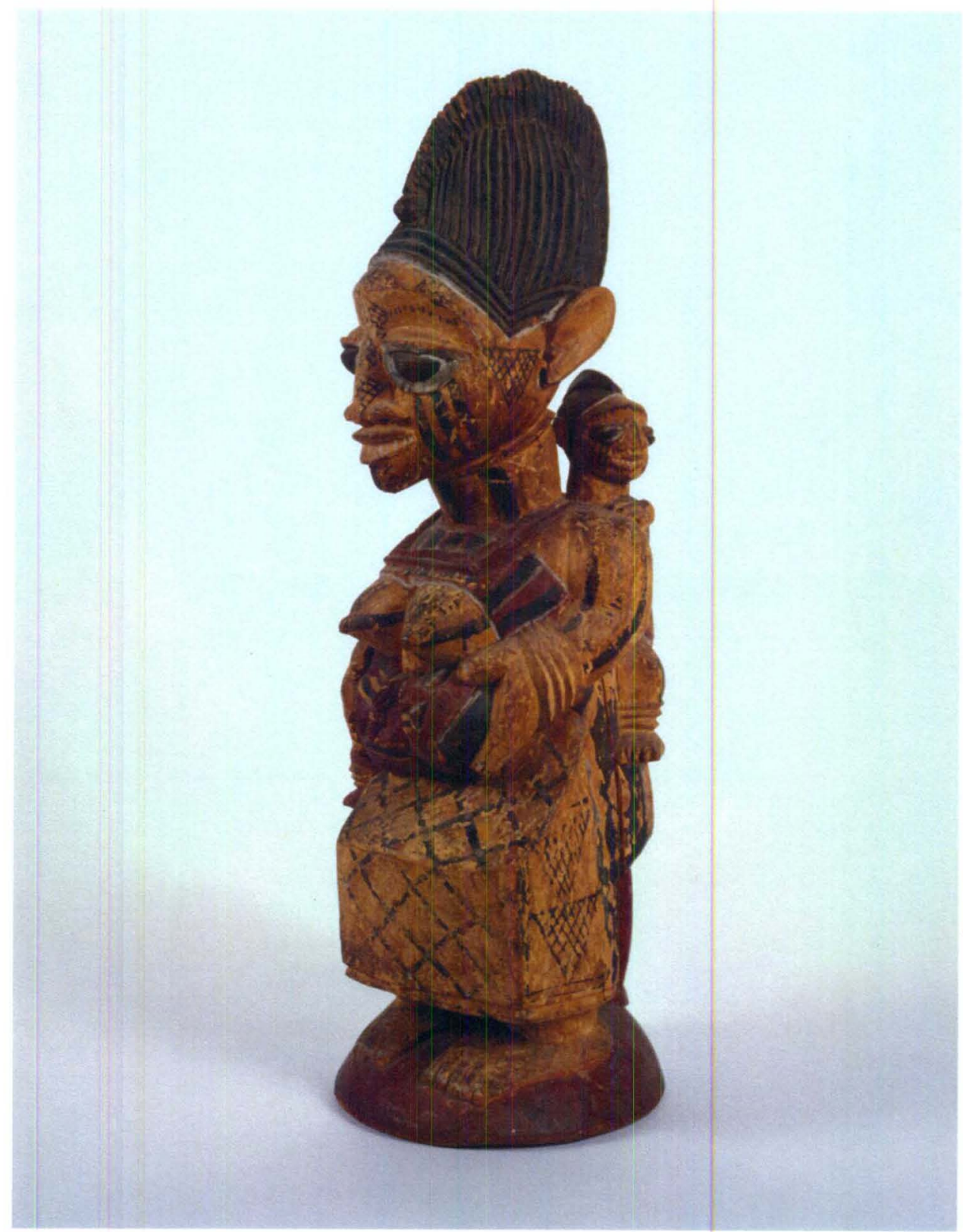

Figure 13

Agbonbiofe Adeshina

Nigerian, died 1945

Mother of Twins (Iya Ibeji), Early $20^{\text {th }}$ century

Wood, pigment

$25 \% 16 \times 7 \frac{3}{8} \times 7 \frac{7}{8}$ in.

Purchased with funds from Alice Speed Stoll Accessions Trust 2003.14 


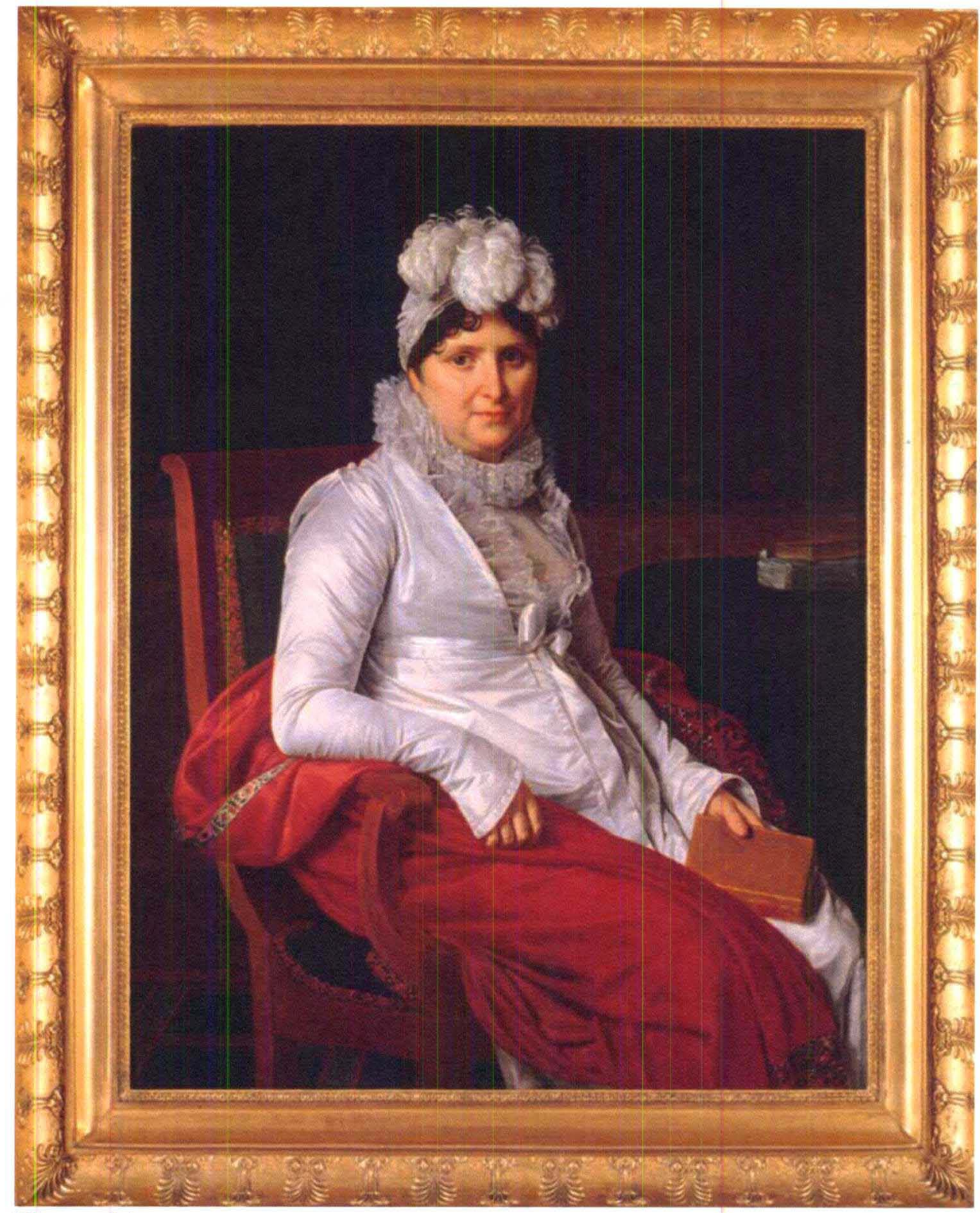

Figure 14

Merry Joseph Blondel

French, 1781-1853

Portrait of Madame Houbigant, born Nicole Deschamps, about 1807 Oil on canvas

$41^{3} / 4 \times 33$ in.

Gift of Mrs. Hattie Bishop Speed, by exchange 1993.17 


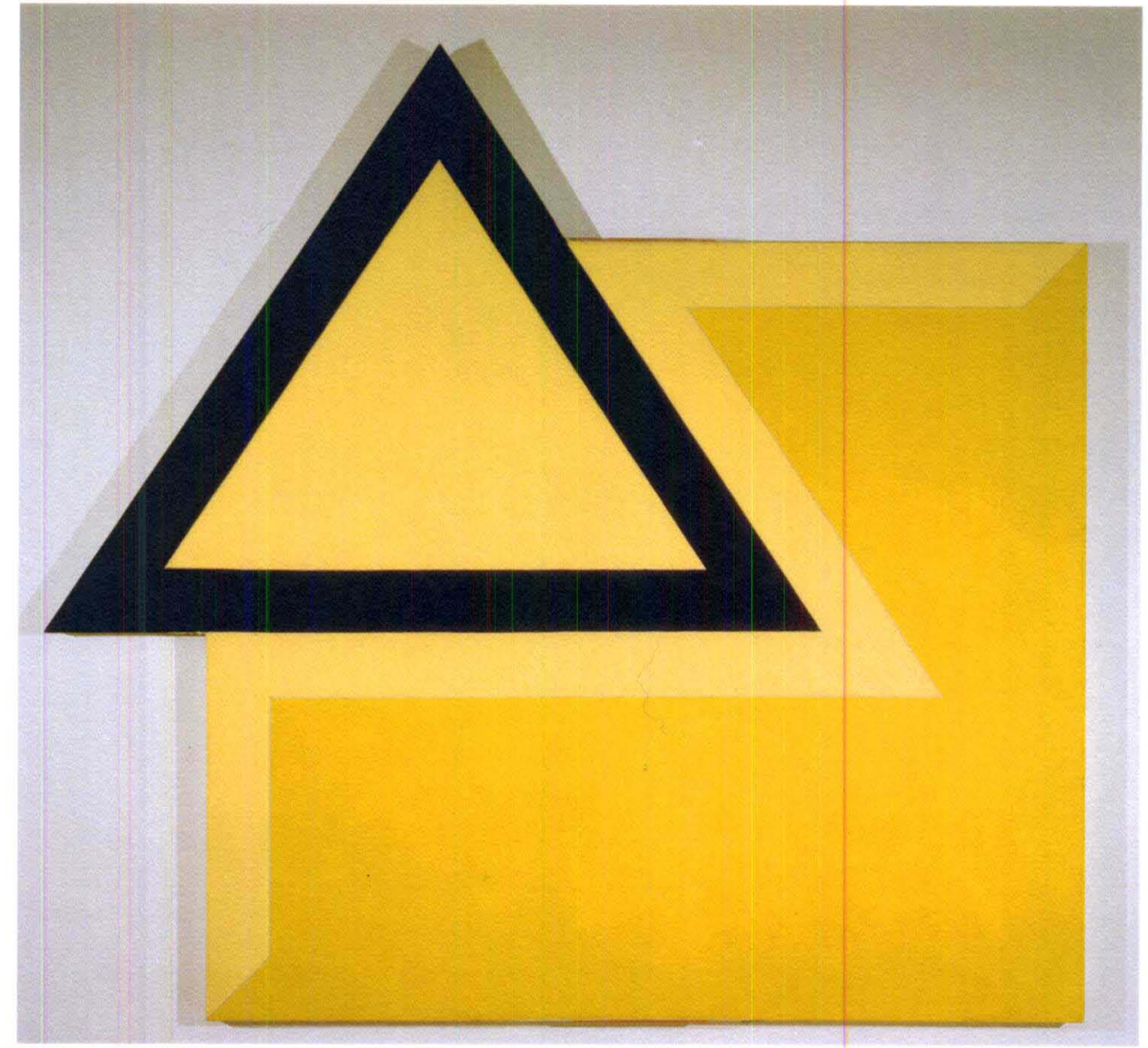

Figure 15

Frank Stella

American, born 1936

Chocorua II, 1966

Fluorescent alkyd and epoxy paints on canvas $120 \frac{3}{8} \times 128^{7} / 16$ in.

Museum Members purchase

1967.44 


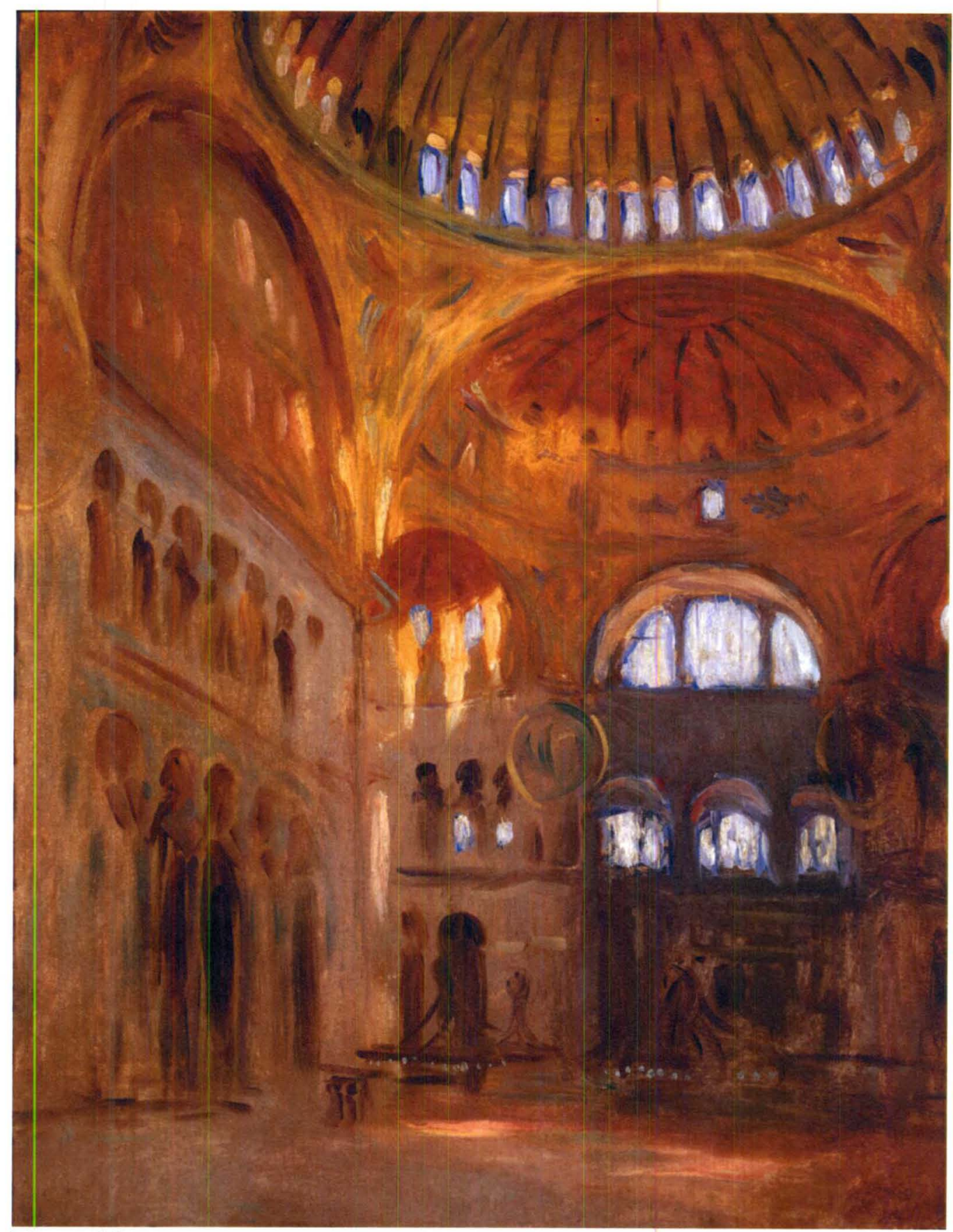

Figure 16

John Singer Sargent

American, 1856-1925

Interior of Santa Sophia, Constantinople, 1891

Oil on canvas

$32 \times 245 / 8$ in.

Purchase, Museum Art Fund

1960.5 


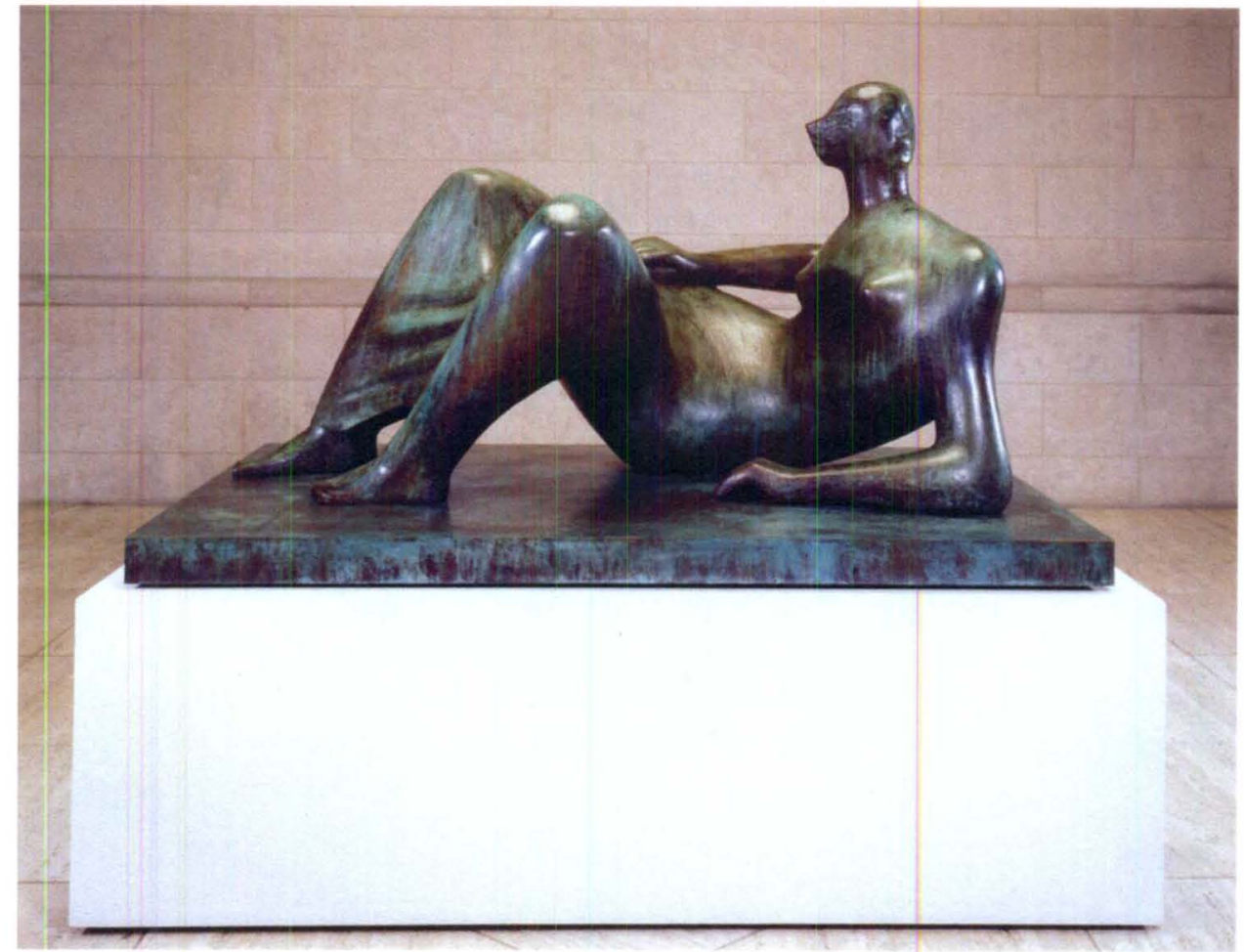

Figure 17

Henry Moore

British, 1898-1986

Reclinging Figure: Angles, 1979

Bronze

$48{ }^{9} / 16 \times 907 / 16 \times 61 \frac{13}{16}$ in.

Gift of Sara Shallenberger Brown in memory of her husband, W.L. Lyons Brown 1981.21 


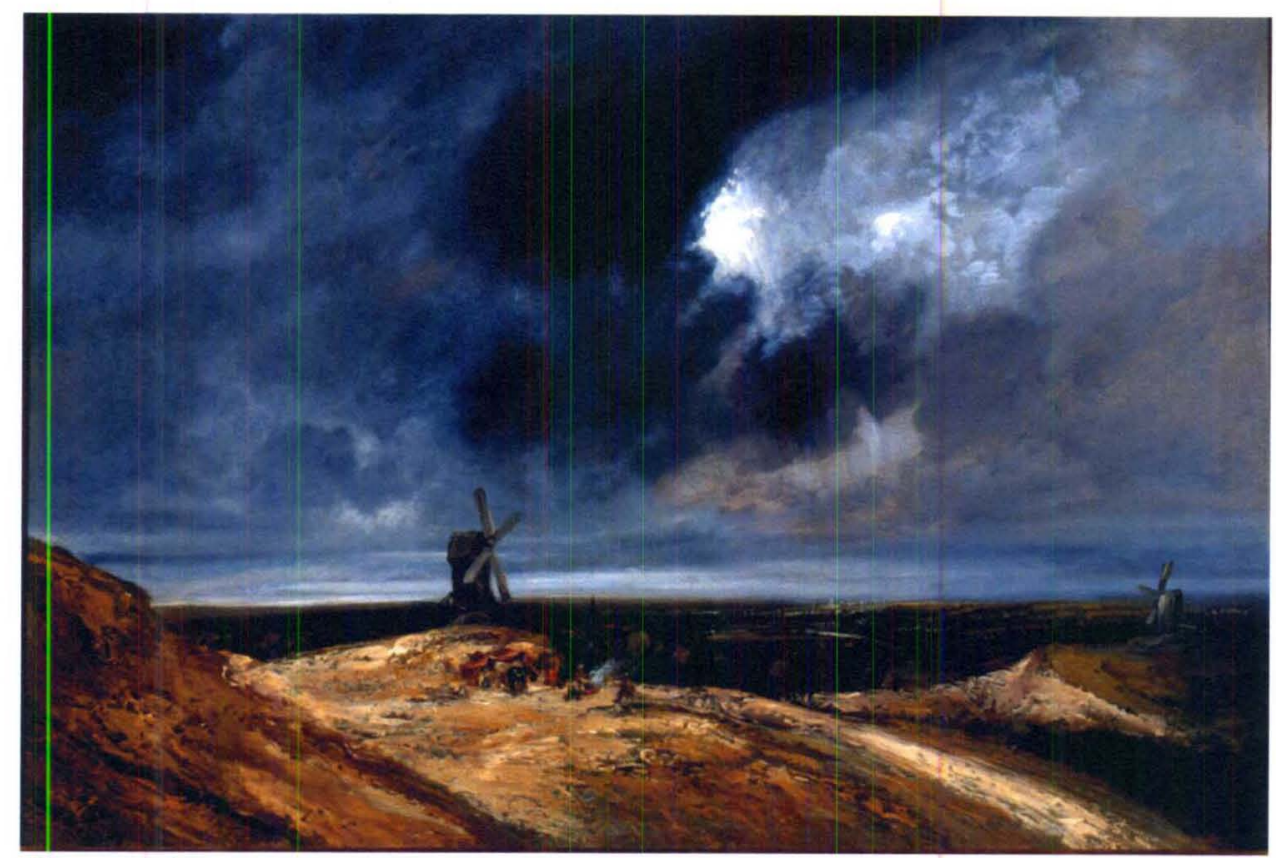

Figure 18

Georges Michel

French, 1763-1843

Landscape wit a Mill with a View of Montmarte, after 1830

Oil on paper laid down on canvas

$297 / 8 \times 41 \frac{1}{2}$ in.

Gift of the Charter Collectors

2002.18 


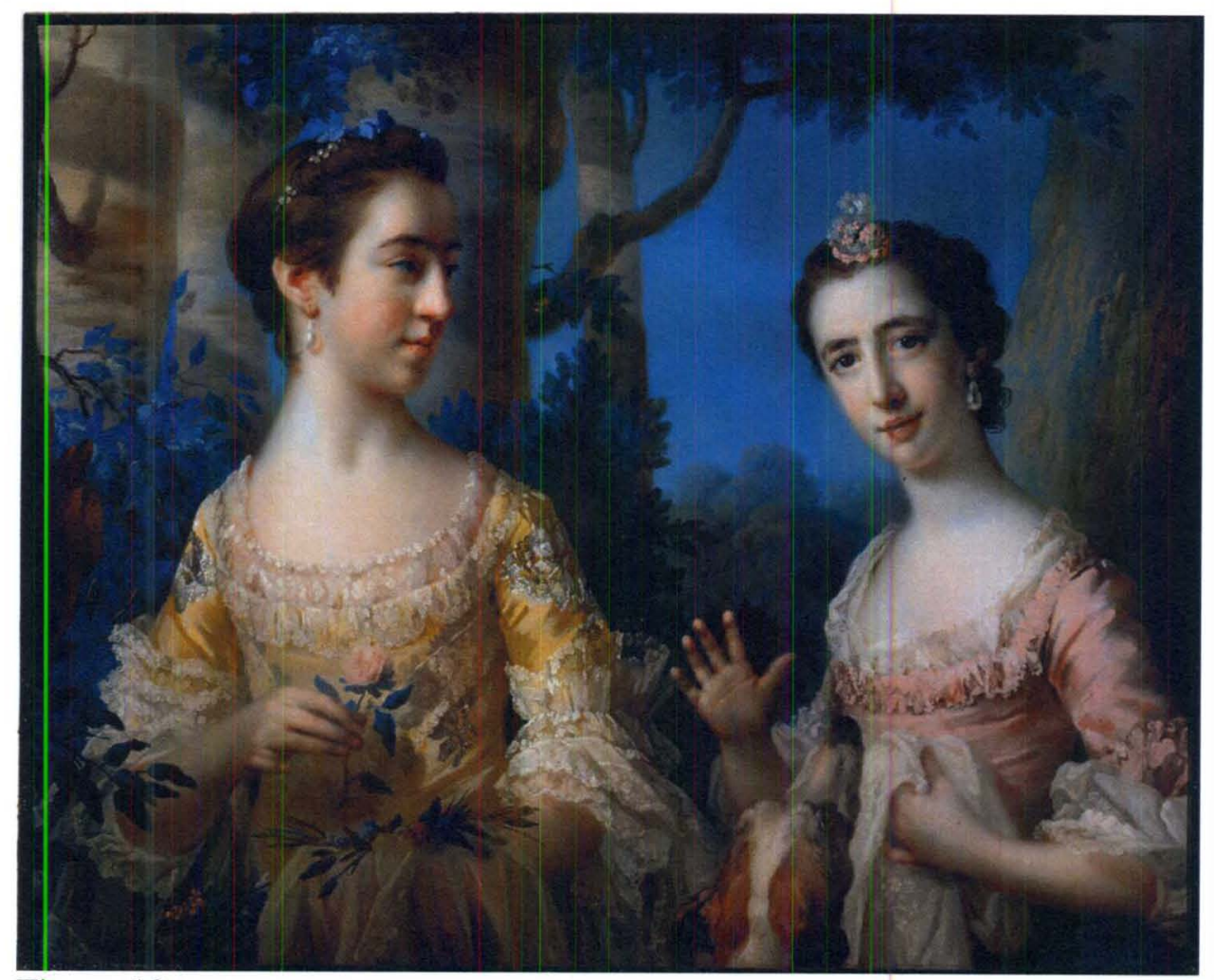

Figure 19

Francis Cotes

English, 1726-1770

Double Portrait, 1757

Pastel on blue laid paper mounted on canvas $27 \times 33 \%$ in.

Bequest of Alice Speed Stoll 1998.6.2 


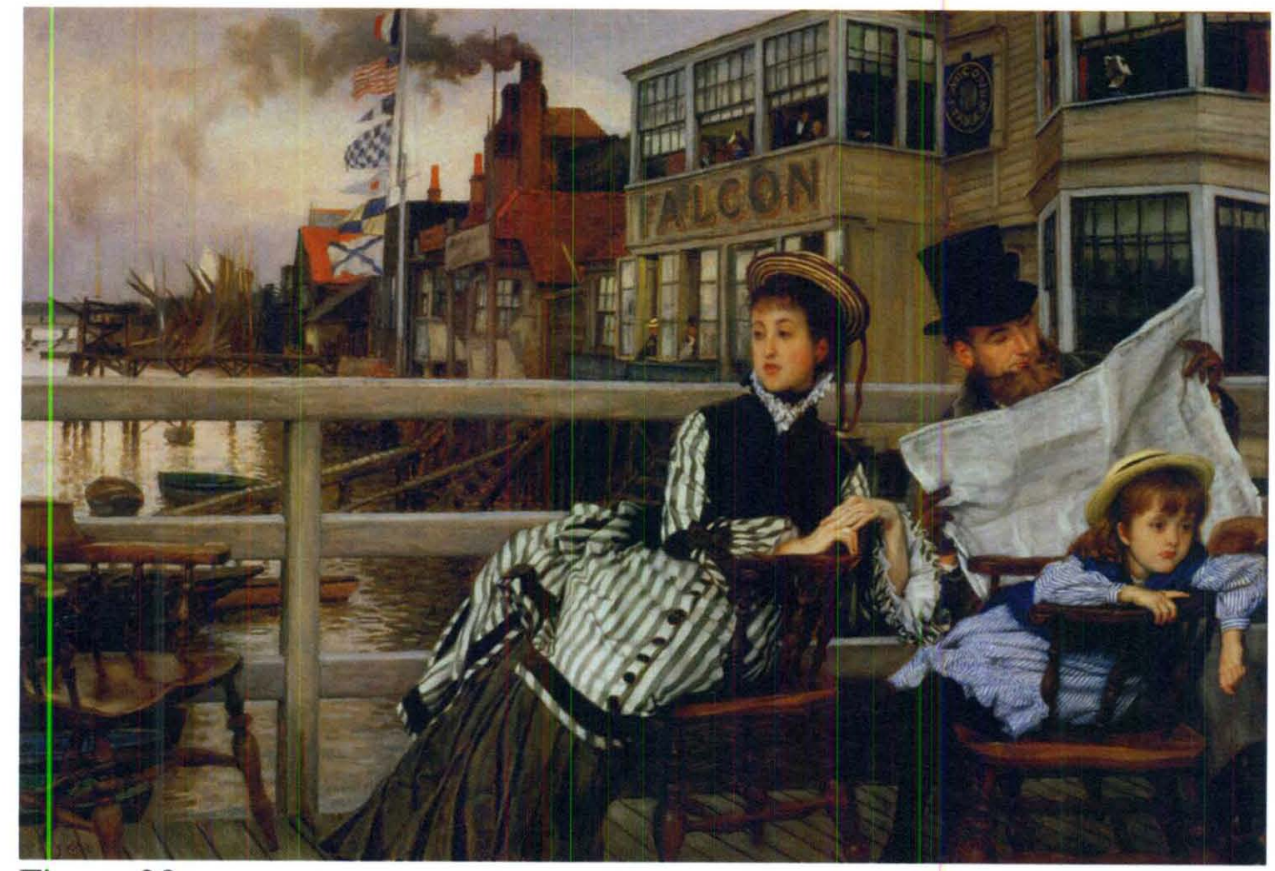

Figure 20

James Tissot

French, 1836-1902

Waiting for the Ferry at the falcon Tavern, about 1874

Oil on canvas

$26^{1 / 4} \times 38^{3} / 16$ in.

Gift of Mrs. Blakemore Wheeler

1963.41 


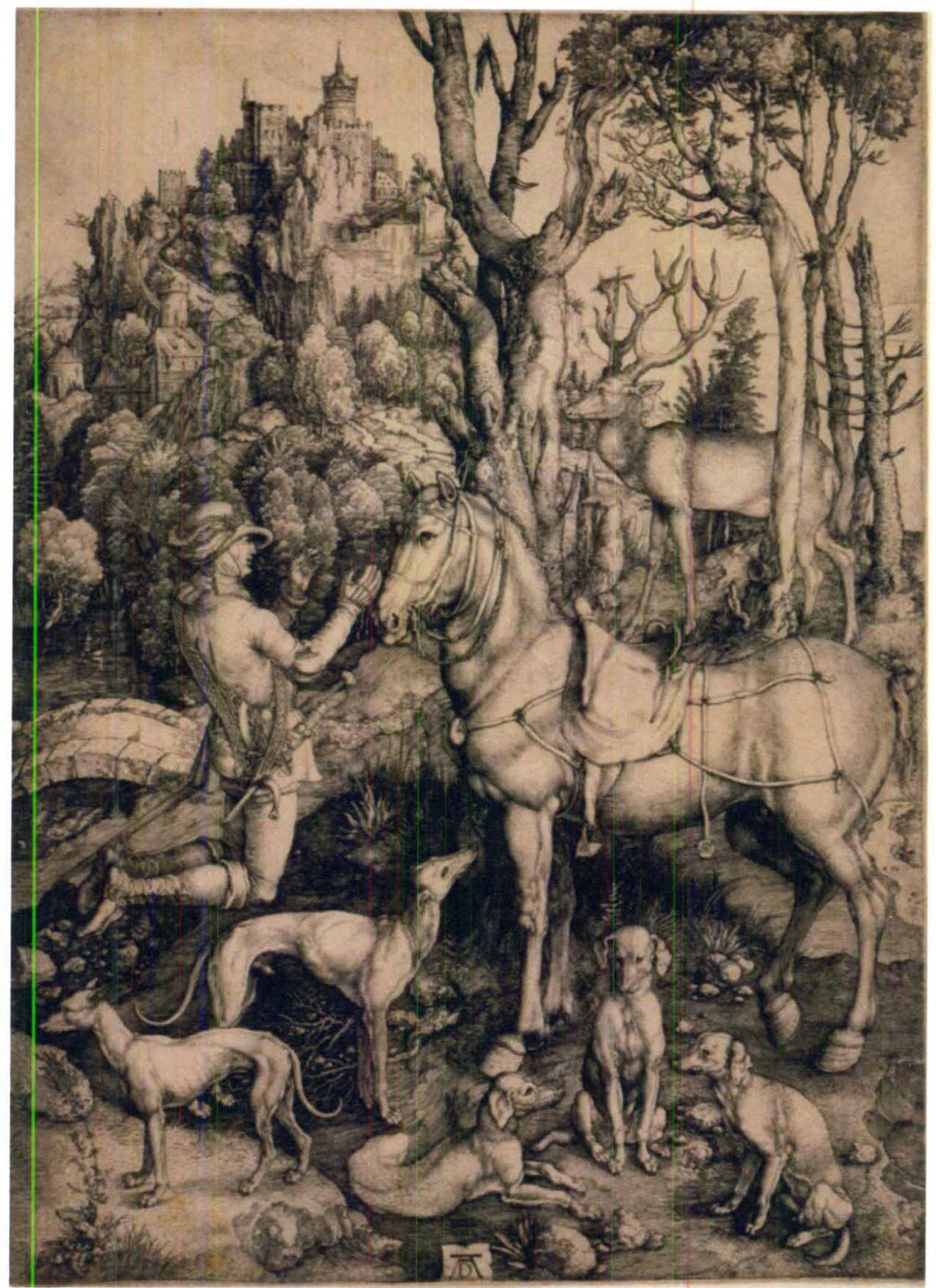

Figure 21

Albrecht Dürer

German, 1471-1528

Saint Eustace, about 1501

Engraving on paper

$14^{1 / 8} \times 10^{1 / 4}$ in

Gift of the Museum Collectors

1968.27 


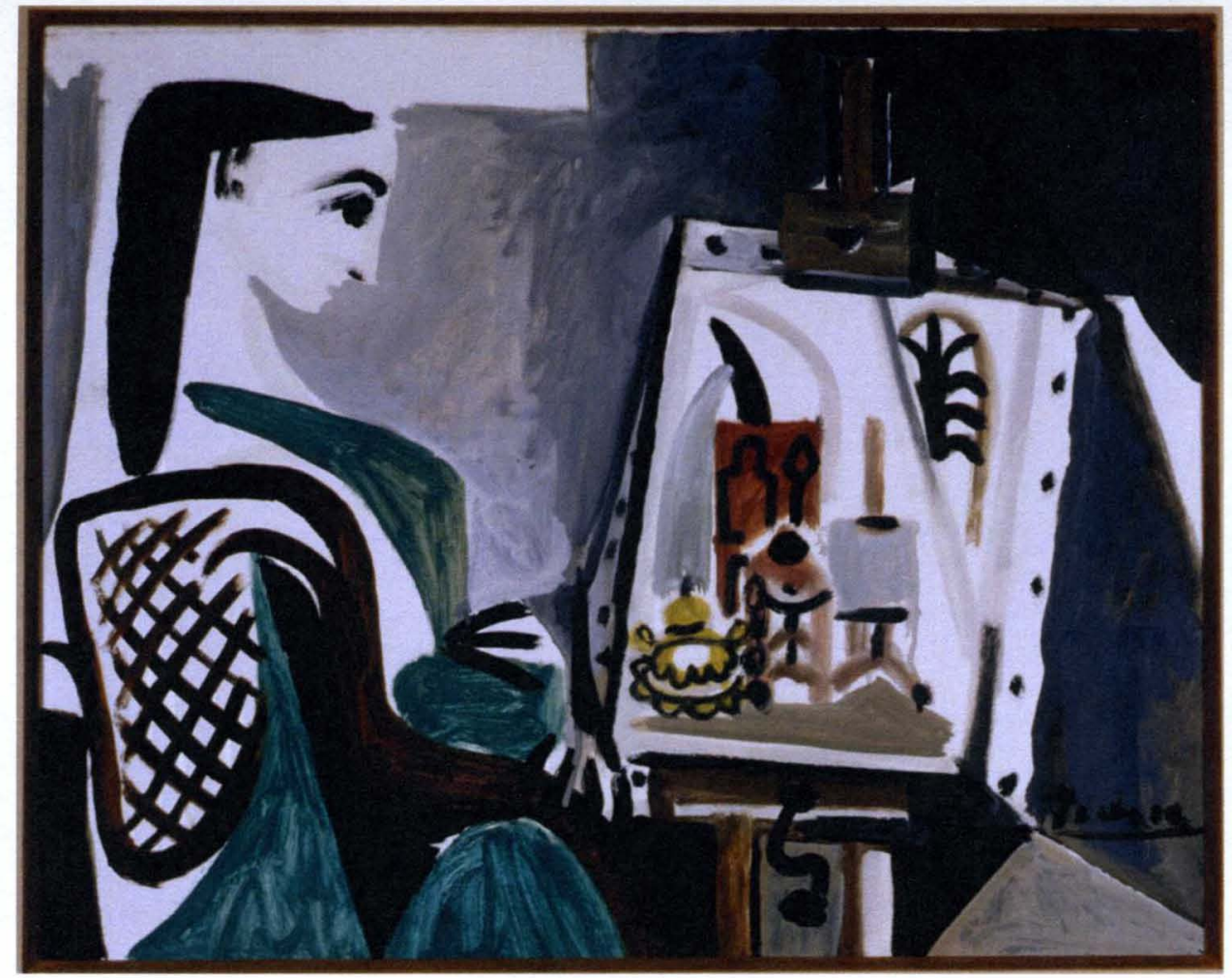

Figure 22

Pablo Picasso

Spanish, 1881-1973

Woman in the Studio (Jacqueline Roque), 1956

Oil on canvas

$18 \times 22 \frac{1}{2}$ in.

Bequest from the Nancy Batson Rash and Dillman A. Rash Collection 1998.19.5 
Exploring Color through the Art of the Speed Art Museum

Spring 2009

**This tour borrowed elements from the Speed's tour "Subject Matter and Vocabulary" a tour for fourth and fifth grades, written in Fall 2004. 


\title{
EXPLORING COLOR IN ART
}

\author{
A Tour for Grades $4 \& 5$ (intermediate)
}

\section{Objectives:}

-To explore color in artworks, in order to learn more about color theory and culture.

-To use color as a means to engage children in art.

-To utilize the Kentucky core content that pertains to color in the tour.

-To provide activities which help the children better understand color, through a hands on approach.

-To use works in the Speed's collection as a tool to engage color.

-To promote critical thinking skills when it comes to color interpretation.

Teaching Tips:

As is the Speed's policy, this tour, as well as all tours in the Speed, should use inquirybased, interactive touring strategies. It is important to remember that active learning is a successful learning strategy for students.

Reading through my thesis is also recommended. There are a variety concepts mentioned which may help lead the tour, either directly or indirectly.

The artworks in the tour are suggested, if you believe you can convey the idea better with another artwork, feel free to do so. It is even better if you can touch on more then one principle with an artwork, especially in a time crunch.

Select a few of the discussion questions and activities for each artwork. If you give the tour multiple times, try different ones. There should be at least one color activity per tour.

Vary the pace of your tour and pay attention to each group's behavior and needs. For example, if attention is waning, pick up the pace; if the students are over-stimulated, try less vigorous strategies.

Introductions, Transitions and Conclusions:

Docents should use the standard form of introductions: welcome the group, introduce himself/herself and the main tour themes, explain the rules in an age-appropriate manner, and clarify how questions/comments will be handled.

Docents should compose their own transitions to smoothly incorporate the works of art they select.

Order is important in this tour. Take the recommended order for discussing the concepts and take into account where the artworks you chose are located and decide on a path which is successful for both. 
Conclusions again follow the standard format: thank the group, praise their behavior (if appropriate), and encourage students to visit again. 
Working with Intermediate Students: Grades 4 \& 5

Student Personality Characteristics:

-More focused then primary students

-"Choose me, choose me" - explain first that you will not call on a person who is calling out.

-Open to more in-depth exploration

-Still impressionable

-Dramatic

-Need praise

-Want to be the helper

-Development of some "attitude"

-Challenging at times

-Can compare and contrast art

-Opinionated about others art

-Capable of higher-level abstract thinking

-More self-aware then primary students

-Start getting frustrated because their artwork doesn't match the ideas in their heads

-Able to reflect on their own artwork

-More street smart than you think

Best Ways to Engage Intermediate Students:

-Use praise, encourage without overdoing it

-They like challenging projects - so challenge them

-Use special privileges so as to combat jaded attitudes

-Use their sense of humor or ability to understand puns/jokes as a means to reach them

-They like "hands-on"

-They respond to discovering on their own

-They like competitive games

-Have them discuss important issues

-Use sincere complements when earned

-Appeal to their "growing up" status and "role model" status 


\section{Particulars in giving this tour:}

Before the tour ask the students some questions to see how advanced they are, adjust appropriately.

Many works on the tour can and should be used to teach more then once principle.

Part One takes precedent over Part Two, in a time crunch.

The artworks are not always up, or you may not feel comfortable with a certain piece, therefore feel free to replace an artwork on the tour with another if it will better serve to convey the ideas.

Talk about 4-6 works at around ten minutes each.

A color wheel is vital to give this tour, a prism may also, be helpful. 


\section{$\underline{\text { Core Content Addressed in Tour }}$}

Kentucky Department of Education

Core Content for Arts and Humanities Assessment Version 4.1

$$
\text { for } 4^{\text {th }} \text { Grade }
$$

\section{AH-04-1.4.1}

Students will identify or describe elements of art and principles of design in works of art.

DOK 2

\section{Elements of art:}

Line, Shape, Form, Texture and Color (primary and secondary hues) and color schemes (warm, cool, neutral - black, white, gray, sometimes brown/beige as earth tones)

\section{Principles of design:}

Organization of visual compositions: Emphasis (focal point), Pattern, Balance (symmetry), Contrast (e.g., black/white, rough/smooth)

\section{AH-04-1.4.2}

Students will identify or describe how an artist uses various media and processes.

\section{DOK 2}

Media (plural) / medium (singular): (used to produce artworks)

Two-dimensional - crayon, pencil, paint, fabric, yarn, paper

Three-dimensional - clay, papier-mâché

\section{Art processes:}

Two-dimensional - drawing, painting, fiber art (e.g., fabric printing, stamping), collage Three-dimensional - pottery, sculpture, fiber art (e.g., constructing with fiber, weaving, quilting)

Subject matter: (e.g., landscape, portrait, still life)

\section{AH-04-2.4.1}

Students will identify how visual art has been a part of cultures and time periods throughout history.

DOK 2

\section{Cultures:}

Native American, Traditional Appalachian

West African

Similarities and differences in the use of art (e.g., purposes for creating art, folk art) and elements of art and principles of design among cultures (e.g., how line, color, pattern, etc. are used in artworks), media in relation to these cultures (e.g., wood, fiber) 
Periods:

Colonial American

European influences in American visual art, similarities between the visual art in the American colonies and the cities of Europe (The influence of Europe was very strong in the colonies due to the movement of settlers from Europe to America.)

Native American includes period in North America before European settlement

\author{
Kentucky Department of Education \\ Core Content for Science Assessment Version 4.1 \\ for $4^{\text {th }}$ Grade
}

SC-04-4.6.2

Students will:

- analyze data/evidence of the Sun providing light and heat to earth;

- use data/evidence to substantiate the conclusion that the Sun's light and heat are necessary to sustaining life on Earth.

Simple observations, experiments and data collection begin to reveal that the Sun provides the light and heat necessary to maintain the temperature of Earth. Evidence collected and analyzed should be used to substantiate the conclusion that the sun's light and heat are necessary to sustain life on Earth.

DOK 3

SC-04-4.6.4

Students will:

- analyze models/representations of light in order to generalize about the behavior of light;

- represent the path of light as it interacts with a variety of surfaces (reflecting, refracting, absorbing).

Light can be observed as traveling in a straight line until it strikes an object. Light can be reflected by a shiny object (e.g., mirror, spoon), refracted by a lens (e.g., magnifying glass, eyeglasses), or absorbed by an object (e.g., dark surface).

DOK 3 
$\underline{\text { Important Vocabulary }}$

After-Image- The illusion of color and shape produce in the visual apparatus after staring at a strong color for some time. A positive after-image is the same color as the original: a negative after image is its complement.

Analogous Color Scheme- A color scheme that uses colors that are adjacent on the color wheel.

Color scheme- Combinations of pure hues and their variations that are harmonious.

Color Wheel- Conventional means of arranging the primary colors (blue, red, and yellow), their principal mixtures or secondary colors (orange, green and purple), and other principal mixtures or hues, so as to demonstrate their sequential relationship. Colors that fall directly opposite one another in the color circle are called complementary colors. (See Page 74)

Complementary Color- Two colors opposite on the color wheel. Consisting of a primary color and the secondary color produced by the other two primaries on the color wheel makes it seem brighter or stronger. For example, red strengthens green, blue strengthens orange, and yellow strengthens purple.

Cones- Special cells in the retina at the back of the eye which enable us to distinguish hues in daylight. There are three kinds: Red, Blue and Green.

Cool Color- A color that suggests sensations of coolness, such as blue or its associated hues, green, purple, blue-green, and blue-violet. In painting, cool colors appear to recede from the picture plane and therefore suggest depth.

Grayscale- A color scheme which only uses, black white and gray.

Monochromatic- referring to a color combination based on variations in value and saturation of a single hue, perhaps with the addition of some neutral colors.

Neutral Color Scheme- a color scheme which contains only colors such as black, white, brown or gray that does not contain any pure hue.

Primary Colors- The colors from which all others are derived, and which cannot be resolved or decomposed into other colors.

Pigments: Red, Blue and Yellow

Light: Red, Blue and Green

Printing: Magenta, Cyan and Yellow 
Secondary Color- A hue resulting from the mixing of a primary hue and an adjacent primary hue. Also termed intermediate hue.

Pigment: Green, Orange and Purple

Light: Magenta, Cyan and Yellow

Printing: Red, Blue and Green

Shade- The result of a mixture of a pure hue with black.

Tint- The result of a mixture of a pure hue with white.

Triad color scheme- a color scheme formed by three hues that are equidistant from each other on the color wheel.

Warm Color- A color which suggests sensations of warmness, such as red, orange or yellow. Warm colors tend to project from the picture plane.

Value- The lightness or darkness of a color.

Definitions Adapted from:

http://student.ccbcmd.edu/ srikin/Home-base/ARTS1 18SITE/GLOSSARYa\%20rt118.htm

http://www.teachnet.ie/cwinters/glossary.htm 


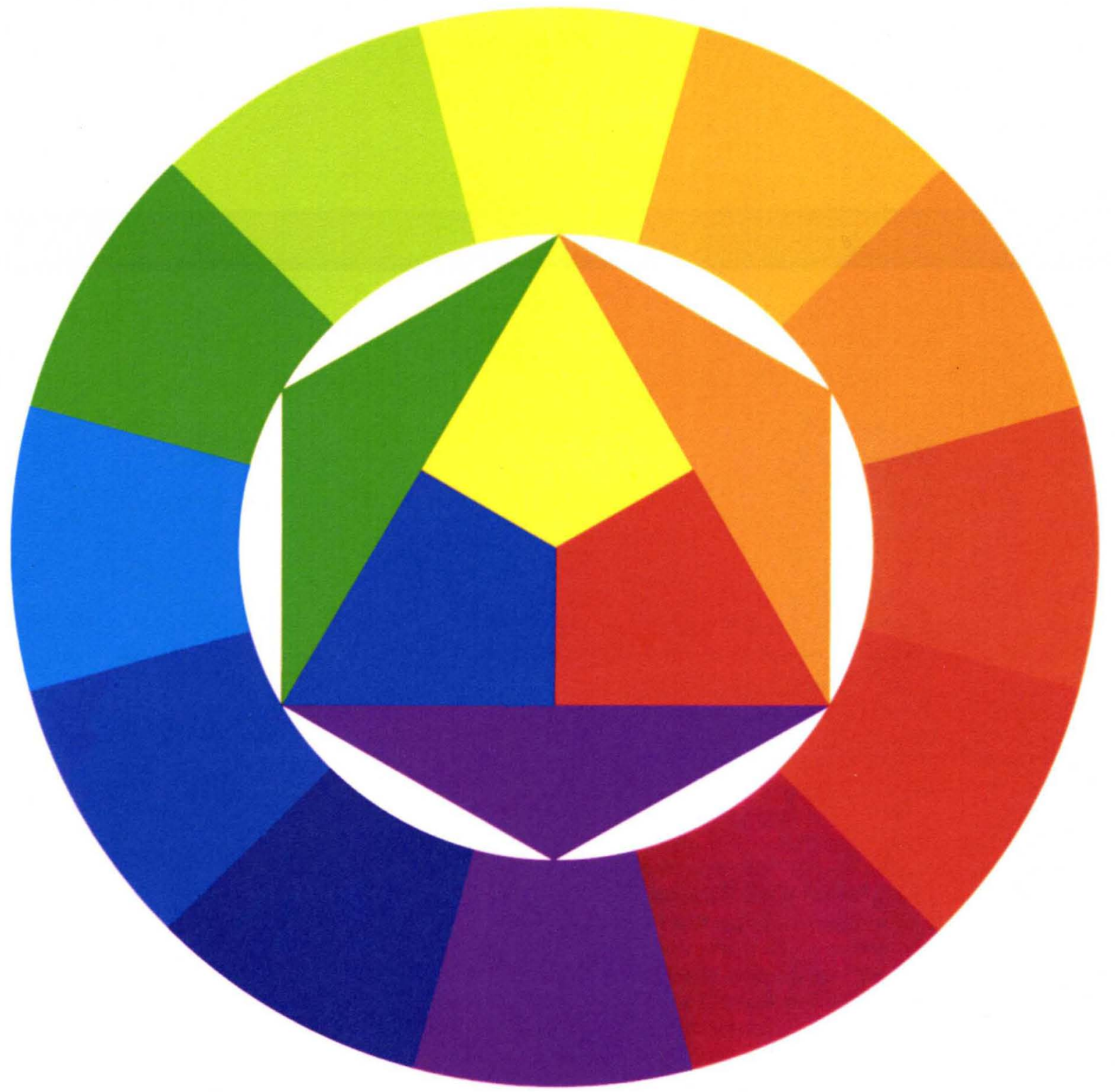

Color Wheel

A wheel like this should be used while giving the tour Image source: http://faculty.fortlewis.edu/lancaster_k/video304/colorwheel.jpg 
Part One:

Exploring Color Relationships

$\underline{\text { Plimary Colors }}$

Lakota Sioux, Northern Plains

Quiver and Bow Case with Arrows, War shirt, and Quirt, about 1873

Tanned deer hide, pigments, glass beads, wool cloth

Nluseum Purchase 1937.68

OR

Pjeter Cornelisz. van Slingeland

Dutch, 1640-1691

Tine Interior of a Kitchen, about 1658

Oil on panel

Gift of the Charter Collectors and Mrs. Blakemore Wheeler, Mr. And Mrs. Barry

Bingham, Sr., Mrs. Hattie Bishop Speed Mrs. E. Gary Sutcliffe, Mrs. Margaret Bridwell, Mrs. Oscar Fenley, and Mr. And Mrs. Klaus G. Perls, by exchange 1992.23

Goal

To look at primary colors, and study how they affect the piece.

\section{Discussion Questions}

Before discussing the work, ask the students to name the primary colors.

How do the primary colored beads look on these works? How would it affect the piece if they were different colors, like pink, purple and green?

Why do you think the Native Americans chose these colors? Was it entirely deliberate, or was there some aspect of the random and/or convenience involved? Example: Did they choose these colors because they formed the primary triad and complemented each other, or were they just the most abundant colors, because they are distinct?

In the van Sligeland, the primary colors are bright and vibrant, while the rest of the piece is rather neutral. How does this serve to enhance the colors? How do the colors enhance ec.ch other? Do you think the use of primary colors was deliberate?

\section{Activity}

Use the color wheel. Show the students the primary colors on it, and how they are equal distances apart form each other. 
Alternative Works

Lakota Sioux, South Dakota, Dress

F.ancis Cotes, Double Portrait

Joseph Stella, The Peach

Jim Leedy, Colorful Vessel

Narc Chagall, Waiting (L'Attende)

Yinka Shonibare, MBE, Three Graces

$\underline{\text { Core Content }}$

AH-04-1.4.1

AH-04-1.4.2

$\mathrm{AH}-04-2.4 .1$ 


\section{$\underline{\text { W}} \underline{\text { arm and Cool Colors }}$}

Yinka Shonibare, MBE

British, born 1962

Three Graces, 2001

Printed cotton textile, three fiberglass mannequins, three aluminum bases

P.urchased with funds from the Alice Speed Stoll Accessions Trust 2002.6 a-c

OR

Joseph Stella

American, 1877-1946

The Peach, about 1929

Oil on Canvas

Partial and Promised gift, anonymous Louisville collection 2006.7.4

\section{$\underline{\text { Goal }}$}

To look at warm colors in artwork and discuss their affect on the artwork and the viewer.

\section{Discussion Questions}

Ask the children to name the warm colors. Relate the idea of fire to them if they are having trouble.

Have the children relate how the pieces make them feel. Perhaps be more specific and ask how the colors make them feel.

How would the piece be different if it was composed with cool colors?

Both pieces have a cool color, blue, in them. Does this affect the warm colors? Does it cool them down or intensify them?

Core Content

AH-04-1.4.1

AH-04-1.4.2

AH-04-2.4.1 
Claude Monet

French, 1840-1926

The Church at Varengeville, Grey Weather, 1882

Oil on Canvas

Bequest of Mrs. Blakemore Wheeler 1964.31.20

OR

Marc Chagall

French, born Belorussia, 1887-1985

Waiting (L'Attente), 1967

Oil on canvas

Bequest from the Nancy Batson Rash and Dillman A. Rash Collection 1998.19.1

Goal

To look at cool colors in artwork and discuss their affect on the artwork and the viewer.

\section{Discussion Questions}

Ask the children to name the cool colors. Relate the ideas of water, ice and other calming things to them if they are having trouble.

Have the children relate how the pieces make them feel. Perhaps be more specific and ask how the colors make them feel.

How would the piece be different if it was composed with warm colors?

Blue is traditionally associated with sadness. Does it convey that in these pieces? Or does it function more as a calming color?

\section{$\underline{\text { Alternative Works }}$}

Attributed to Pierre Courteys, The Tree of Jesse

Gustave Courbet, La Dent de Jaman

Marsden Hartley, Maritime Alps, Vence, No. 9

Core Content

AH-04-1.4.1

AH-04-1.4.2 


\section{Complementary/Secondary Colors}

William Mason Brown

American, 1828-1898

Raspberries, about 1870

Oil on canvas

Gift of Mrs. Hattie Bishop Speed 1927.29

OR

Barbara Kruger

American, born 1945

Untitled (Talk Like Us), 1994

Photographic screenprint on Plexiglass

Gift of Mrs. Hattie Bishop Speed, by exchange 1994.3.2

G.oal

To explore complementary colors

\section{$\underline{\text { Disscussion Questions }}$}

Ask the students to name the complementary colors.

Discuss what complementary colors do. Do the children realize the affect they have on each other, mutual enhancement?

If discussing Kruger's work address that the colors are not pure complementary, they do function the same way however. Ask the students how many pairs of complementaries there are. What about Orange-Yellow and Blue-Violet? Explain that there are an infinite arcount of complementaries and even more near complementaries.

Review the fact that each primary's complement is a mixture of the other two primaries. Relate complements making each other stand out to the primary triad doing the same.

\section{Activities}

Use the color wheel, show them complementary colors.

Negative Image: Have them stare at an image for a minute. After when they look at a blank white surface the image will be in its complements.

Fruit exercise: Take a red apple, green pear and yellow banana. Place them on red, green and yellow backgrounds. Observe how they look differently against each one. The complements, red on green or green on red, should look the most striking. 
Albers: Have pieces of paper or cardboard of different colors, in two sizes. Experiment with different combinations. How do colors change depending on what color they are p.aced up against? Relate this to complementary colors.

\section{Alternative Works}

Nicolas de Largillére, Portrait of Mademoiselle Duclos in the Role of Ariadne

Probably made by Mary Mize, Quilt

Olaf Rude, Interior with Woman in Red Dress

Edwin Ambrose Webster, Red House, Bermuda

Helen Frankenthaler, Situation

Elmer Bischoff, Four Figures and Two Boats

Howard Hodgkin, Venice, Morning

Core Content

AH-04-1.4.1

AH-04-1.4.2

SC-04-4.6.4 
Analogous Colors

W'illiam Mason Brown

American, 1828-1898

Peaches, about $1870 ? ? ? ?$

Oil on canvas

Gift of Mrs. Hattie Bishop Speed 1927.28

OR

Paul Cézanne

French, 1839-1906

Two Apples on a Table, about 1895-1900

Oil on Canvas

Purchased with funds from the Alice Speed Stoll Accessions Trust and with funds donated by Wayne Perkey and Family, Mrs. W.L. Lyons Brown, Mrs. Harry S. Frazier, Jr., Sandra A. Frazier, Mr. And Mrs. Randall B. Hocknsmith, The University of Loiusville Foundation, Inc., Dr. and Mrs. Condict Moore, Helen Condon Powell, and Mr. And Mrs. Edmund A. Stienbeck, Jr. 2000.21

Goal

To learn about analogous color schemes

\section{Discussion Questions}

Ask the students if they know what an analogous color scheme is. It is one of the hardest color schemes to grasp, so it may take some explaining.

\section{$\underline{\text { Activities }}$}

Use the color wheel to show them different examples of analogous color schemes.

When looking at the art pieces have them pick out the colors and point out the colors used on the color wheel. Does it go from orange to green or just orange to yellow?

\section{Alternative Works}

Plains Apache, Moccasins

Flemish, Bruges, The Penitent Magdalene

Workshop of Guido Durantino, Basin

Workshop of the Fontana family, Dish

Gustave Courbet, La Dent de Jaman

Claude Monet, The Church at Varengeville, Grey Weather

Charles Caryl Coleman, Passion Flowers

Alfred Henry Muer, Landscape 
Mlarsden Hartley, Maritime Alps, Vence, No. 9

Core Content

AH-04-1.4.1

AH-04-1.4.2 


\section{Neutral Colors}

Rembrandt van Rijn

Dutch, 1606-1669

Portrait of a Forty-Year-Old Woman, possibly Marretje Cornelisdr. van Grotewal, 1634 Oil on Panel

Purchased with funds contributed by individuals, corporations, and the entire community of Louisville, as well as the Commonwealth of Kentucky 1977.16

OR

Yoruba people, Nigeria, Ijebu-Ode

Panels, late $19^{\text {th }}$ century

W'ood

Gift of Mrs. William B. Belknap 1976.12.1-3

Agbonbiofe Adeshina

Nigerian, died 1945

Mother of Twins (Iya Ibeji), Early $20^{\text {th }}$ century

Wood, pigment

Purchased with funds from Alice Speed Stoll Accessions Trust 2003.14

Goal

To look at works with Neutral color schemes

Discussion Questions

How does a color scheme neutral colors work the same/ differently then black and white alone?

Compare and contrast the neutral colors of the Rembrandt and neutral colors of the African pieces. How are they alike/different? Functionally why do you think they are different?

Most African art is neutral toned. What does this mean to you? Is it symbolic of being closer to the earth?

\section{Alternative Works}

Roman, Sarcophagus

Songye people, Democratic Republic of the Congo, Ceremonial Axes

Johannes Cornelisz. Verspronck, Portrait of a Man

Eugène Delacroix, Greenwich

William Bailey, Still Life of 10 eggs, White Vase, Blue and White Vase and Enamel Cup 
Core Content

AH-04-1.4.1

AH-04-1.4.2

AH-04-2.4.1 


\section{Part Two: Exploring Color's meanings}

$\underline{\text { Red and White }}$

Merry Joseph Blondel

French, 1781-1853

Portrait of Madame Houbigant, born Nicole Deschamps, about 1807

Oil on canvas

Gift of Mrs. Hattie Bishop Speed, by exchange 1993.17

Goal

To discovery how red and white work in an artwork

Discussion Questions

$\mathrm{W}^{\prime}$ hat does the white convey to you in this piece? Pureness? Untouchability? Properness?

What does the red convey? What does red usually convey?

How does the Red and White work and look together in this piece?

Alternative Works

Randolph Rogers, Nydia, the Blind Flower Girl of Pompeii

Polly Apfelbaum, Wallflowers (Mixed Emotions)

Ghada Amer, The Big Red Rose-RFGA

Core Content

AH-04-1.4.2 


\section{Yellow and Gold}

Frank Stella

American, born 1936

Chocorua II, 1966

Fluorescent alkyd and epoxy paints on canvas

Museum Members purchase 1967.44

\section{AND}

John Singer Sargent

American, 1856-1925

Interior of Santa Sophia, Constantinople, 1891

Oil on canvas

Purchase, Museum Art Fund 1960.5

\section{Goal}

To explore yellow and gold in art

\section{Discussion Questions}

How does this, or these, are works make you feel? Happy? Energetic? What emotions do they convey?

How are they alike? How are thy different? Yellow and gold really are not all that different, and are usually used as synonyms, how do they work completely differently in these two pieces? What does yellow do that gold can't? What does gold do that yellow can't?

\section{Core Content}

AH-04-1.4.2 


\section{Green}

Henry Moore

British, 1898-1986

Reclining Figure: Angles, 1979

Bronze

Gift of Sara Shallenberger Brown in memory of her husband, W.L. Lyons Brown 1981.21

\section{Goal}

To explore the color green in an artwork

\section{Discussion Questions}

Ask the students what the sculpture looks like to them. Some students may suggest a landscape. If they do not, present the idea yourself. What causes the sculpture to look like a landscape? The form? Does the green color contribute? How does the color of nature help this illusion?

What associations could the green color create? The form is obviously female; does that contribute to the meaning of the color?

Core Content

AH-04-1.4.2 
Black and Blue

Georges Michel

French, 1763-1843

Landscape wit a Mill with a View of Montmarte, after 1830

Oil on paper laid down on canvas

Gift of the Charter Collectors 2002.18

Goal

To explore the use of black in art

Discussion Questions

How does black function in this work? Does it affect the mood? Would it be considerably different if it was bright and colorful?

Is black always sad and dreary? Is it here?

Alternative Work

James Abbott McNeill Whistler, Nocturne

Core Content

AH-04-1.4.2 
Francis Cotes

English, 1726-1770

Double Portrait, 1757

Pastel on blue laid paper mounted on canvas

Bequest of Alice Speed Stoll 1998.6.2

$\underline{\text { Goal }}$

To explore blue in art

\section{Discussion Questions}

How does blue make you feel in this work?

Blue isn't extremely prevalent in the work. But it still has a definite affect. Do you agree? Why or why not? What is the affect or mood it conveys?

Blue is traditionally associated with sadness and depression. Are those things conveyed here?

\section{Alternate Works}

Augustus Saint-Gaudens, Robert Louis Stevenson

Jim Leedy, Colorful Vessel

Marc Chagall, Waiting (L'Attente)

Core Content

AH-04-1.4.2 
James Tissot

French, 1836-1902

Waiting for the Ferry at the falcon Tavern, about 1874

Oil on canvas

Gift of Mrs. Blakemore Wheeler 1963.41

Goal

To use multiple color theories to interpret one piece

\section{Discussion Questions}

Have the students discuss this work more open ended fashion.

One of they main points to notice is that the painting as a whole is rather neutral, the only place with color, is the little girls dress. It is bright blue. Blue is the color of hope. This is juxtaposed with the more jaded black of the parents' wardrobe.

$\underline{\text { Core Content }}$

AH-04-1.4.2 
Black, White and Gray

Albrecht Dürer

German, 1471-1528

Saint Eustace, about 1501

Engraving on paper

Gift of the Museum Collectors 1968.27

Goal

To explore the absence of color

$\underline{\text { Discussion Questions }}$

What do the kids think about this work? Do they like it less because it is without color? Ask them why that is? Is color that important?

How would this work be different if it was colored? Would it look better? Not as good?

What do the kids think?

\section{$\underline{\text { Alternative Works }}$}

Charles-Nicolas Cochin II, Accession of Louis XV

Joseph Wright of Derby, Young Man in Fur Cap

Thomas de Thomom, A Roman Emperor Petitioned for Clemency

Nicholas Nixon, Glasgow, $K Y$

Andy Warhol, Birmingham Race Riot

$\underline{\text { Core Content }}$

AH-04-1.4.1

$\mathrm{AH}-04-1.4 .2$ 
Pablo Picasso

Spanish, 1881-1973

Woman in the Studio (Jacqueline Roque), 1956

Oil on canvas

Bequest from the Nancy Batson Rash and Dillman A. Rash Collection 1998.19.5

Goal

Learn about Grayscale

Discussion Questions

How would this work be different if it was bright and colorful?

When color is lacking, another element of art is usually focused upon. What do you you think Picasso was focused on?

An interesting aspect to this work is that it is mostly grayscale, however, the artwork, within the artwork (it is a painting of a studio) is in color. Why do you think Picasso did this?

Alternative Works

Joseph Wright of Derby, Young Man in Fur Cap

John James Audubon, Portraits of Mr. and Mrs. James Berthoud

James Abbott McNeill Whistler, Nocturne

Henri Cartier-Bresson, Hyères, France

Nicholas Nixon, Glasgow, $K Y$

Andy Warhol, Birmingham Race Riot

John DeAndrea, Manet: Déjeuner sur l'herbe

Core Content

AH-04-1.4.1

AH-04-1.4.2 


\section{LESSON PLAN OUTLINE}

Day 1

-Administer pre-test

-Review color terms

-Work time for student to draw four fruits: red apple, green pear, yellow banana, fourth fruit of choice

\section{Day 2}

-Discuss some artworks not currently up in the museum (Cotes, Kruger, Durer)

-Review color terms in more depth

-Color scheme activity- Given their four fruits and three pieces of construction paper, the students compose a complementary, analogous and monochromatic color scheme.

Day 3

-Review rules of museum in preparation of visit.

-Review color terms again

-After-image activity- The children color a landscape in complementary colors, I will time them while they stare at it for 30 seconds. Then, they will see the after-image on a white paper. 


\section{ASSESMENT TEST}

1) A red apple sticks out the most on a

A) Red background, because they are the same color.

B) Yellow background, because yellow is a bright color

C) Green background, because it is red's complement

D) Any background, it is always the same

2) If you stare at a colored image for too long, when you look away at a white surface you

will see

A) The image, because your eyes are used to looking at it.

B) The negative of the image, in its complementary colors

C) A black and white version of the image

D) The plain white surface

3) Which of the following is a color triad?
A) Red, Blue, Green
B) Red, Blue, Yellow
C) Green, Orange, Violet
D) $\mathrm{B}$ and $\mathrm{C}$

4) Which trait, that complementary colors have, does the tint of red (pink) and green still have?
A) They are apart from each other on the color wheel.
B) They still make each other stand out.
C) Both A and B
D) None of the above

5) When an image is in black and white it
A) is ugly cause it has no colors
B) focuses on line, value and shape
C) Both A and B
D) None of the above

6) When primary colors are together in a painting they
A) look like brown
B) make each other stand out
C) form a color triad
D) Both B and C 
7) How does a warm color make most people feel?
A) sad
B) tired
C) excited
D) calm

8) How does a cool color make most people feel?
A) angry
B) calm
C) excited
D) jealous

9) Color in art
A) tells stories
B) gives emotions
C) is colorful
D) all of the above

10) The Speed has many artworks that deal with color; name one that is green.
A) Joseph Stella, The Peach
B) Agbonbiofe Adeshina, Mother of Twins
C) Henry Moore, Reclining Figure
D) James Tissot, Waiting for the Ferry

*Bonus*

What is something new, you learned about color? 


\section{CURRICULUM VITAE}

NAME: Jonathan Ratliff

ADDRESS: 550 Central Pike

Harrodsburg, KY 40330

DOB: $\quad$ Pikeville, Kentucky - February 26, 1986

EDUCATION

\& TRAINING: $\quad$ High School Degree

Mercer County High School

2000-2004

B.A. Art

Georgetown College

2004-2007

M.A. Critical and Curatorial Studies

University of Louisville

2007-2009 